\title{
Migration of seismic activity associated with phreatic eruption at Merapi volcano, Indonesia
}

\author{
Jean-Philippe Métaxian ${ }^{\mathrm{a}, \mathrm{b}, *}$, Agus Budi Santoso $^{\mathrm{c}}$, Corentin Caudron ${ }^{\mathrm{a}}$, Noer Cholik ${ }^{\mathrm{c}}$, Claire Labonne ${ }^{\mathrm{d}}$, \\ Natalia Poiata $^{\mathrm{a}, \mathrm{e}}$, François Beauducel ${ }^{\mathrm{a}, \mathrm{b}, \mathrm{c}}$, Vadim Monteiller ${ }^{\mathrm{f}}$, Ahmad Ali Fahmi ${ }^{\mathrm{b}}$, \\ Muchammad Husni Rizal $^{a}$, I.G. Made Agung Nandaka ${ }^{c}$ \\ a Institut de Physique du Globe de Paris, Université de Paris, CNRS, France \\ b ISTerre, IRD R219, CNRS, Université de Savoie Mont Blanc, Le Bourget-du-Lac, France \\ c Center for Volcanology and Geological Hazard Mitigation, Jalan Diponegoro No. 57, 40122 Bandung, Indonesia \\ d CEA, DAM, DIF, 91297 Arpajon, France \\ e National Institute for Earth Physics, 12 Calugareni, Magurele, 077125 Ilfov, Romania \\ ${ }^{\mathrm{f}}$ Laboratoire de Mécanique et d'Acoustique, CNRS, Université Aix Marseille, Centrale Marseille, France
}

\section{A R T I C L E I N F O}

\section{Article history:}

Received 24 May 2019

Received in revised form 17 January 2020

Accepted 27 January 2020

Available online 27 February 2020

\section{Keywords:}

Seismology

Volcano

Merapi

Array

Slowness

Ray tracing

Phreatic

\begin{abstract}
A B S T R A C T
Phreatic activity of Merapi started after nearly 2 years of quiescence following the October-November 2010 eruption which was the largest in more than 100 years. A dozen eruptions identified by visual and/or seismic observations took place between August 2012 and April 2014. We present in this work the results of a detailed analysis of the April 20, 2014 phreatic eruption. We attempted to reconstruct the eruptive process, which lasted for over $30 \mathrm{~min}$. To this end, we determined the wavefield composition by polarization analysis, located high-frequency earthquakes occurring in the initial part of the eruption process and then determined the seismic source migration of low-frequency part of the tremor-like signal [0.3-3 Hz] over time. Source depth of low-frequency signal was obtained by comparing the slowness vector calculated using 3 stations of the seismic antenna with a slowness vector model obtained by ray tracing in the structure, taking into account the topography and a 1D velocity model obtained by spatial auto-correlation analysis. The results allow to distinguish 3 different phases: 1) Highfrequency transients interpreted as the result of a sudden decompression caused by the transition of the volcanic fluid to a gaseous phase that occurred approximately $1.5 \mathrm{~km}$ deep. This decompression process in the hydrothermal system generated a migration of the low-frequency seismic source from $900 \mathrm{~m}$ to $1800 \mathrm{~m}$ above sea level; 2) A second decompression process revealed by high-frequency micro-seismicity and associated to the migration of the low-frequency tremor source which is marked first by a descent phase, followed by a sharp ascent until reaching the surface. The evolution of the back-azimuth during the migration process indicates a slight inclination of the conduit, presumably in the orientation of the dome fracture, in the NW-SE direction. This direction is consistent with the alignment of regional tectonic structures and with the directivity of eruption deposits. 3 ) The seismic source then remains positioned at the altitude of the dome for over $10 \mathrm{~min}$. This phase probably corresponds to the ash emission process. The average migration speed of the low-frequency seismic source from the starting eruptive process to ash emission is about $5 \mathrm{~m} / \mathrm{s}$.
\end{abstract}

(C) 2020 Elsevier B.V. All rights reserved.

\section{Introduction}

Phreatic or phreato-magmatic eruptions are difficult to forecast in comparison to magmatic eruptions. They are not easily detectable by conventional monitoring systems because they involve weak energy and small volumes compared to magmatic eruptions and are triggered by perturbations of the hydrothermal system, which is by definition

* Corresponding author at: Institut de Physique du Globe de Paris, Université de Paris, CNRS, France.

E-mail address: metaxian@ipgp.fr (J.-P. Métaxian). located at shallow depth (Barberi et al., 1992). Even if less energy is involved, non-magmatic eruptions can be violent and destructive. One of the recent phreatic events is the 2014 eruption of Mount Ontake that killed 57 people (Sano et al., 2015).

Analysis of this type of eruption is complicated due to the absence of precursors (Maeda et al., 2015) or its rarity (Caudron et al., 2019). In a post-eruption analysis, Kato et al. (2015) have identified very low amplitude signals on the seismic recordings two weeks before the 2014 Ontake eruption in Japan by using a template matching method. Retrospective analyses found subtle precursors using misfit angles of focal mechanism solutions at Ontake (Terakawa et al., 2016), ground 
deformation at Hakone (Kobayashi et al., 2018) or seismic quiescence at Telica (Roman et al., 2016) prior to phreatic eruptions. Hence if precursors exist, low energy emitted by these processes requires near-field observation and very careful analysis. The last eruption of Ontake shows the importance of studying this type of eruptive activity, to better observe the phreatic eruption processes as well as progress in their understanding.

The occurrence of non-magmatic eruptions nevertheless implies the presence of a magma body a few kilometers below the surface. If a stagnant magma body is present near the surface it can easily trigger phreatomagmatic activity (Rouwet et al., 2014). This is the situation of Merapi whose 2010 eruption left in place a magmatic dome (Jousset et al., 2013). The permanent gas emission activity from the dome and the crater walls attests to the presence of a shallow magma body.

Merapi volcano has shown an unusual activity after the 2010 eruption with the occurrence of several phreatic or phreatomagmatic eruptions between 2012 and 2014. Phreatic activity has occurred a few years after the eruption of 1872 (Voight et al., 2000), whose explosive character was very similar to that of 2010. Therefore, the events of 2012-2014 present an opportunity to better understand the phreatic or phreatomagmatic processes at Merapi volcano.

In the frame of DOMERAPI project, started in 2013, several geophysical arrays were set up on and around Merapi. A seismic array composed of 46 broadband stations was installed on MerapiMerbabu complex for an observation period of 18 months (October 2013-April 2015) with the objective to study the deep structure (Widiyantoro et al., 2018; Ramdhan et al., 2017). Other seismic stations were set up close to the summit. These included a small aperture seismic array installed at the end of 2013 in Pasar Bubar area, situated close to the summit of Merapi. The objective of this instrumentation was to track seismic activity occurring below the crater of Merapi. Seismicity associated to dome growth at Merapi involves different types of events (Budi-Santoso et al., 2013). Most of them (multi-phase, long-period, rockfalls, tremors) are characterized by emergent onsets, lacking clear body-wave phase arrivals, which complicates event location using classical hypocenter determination methods based on phase picking and calculation of traveltimes. One way to overcome this difficulty is to apply an approach using small aperture seismic arrays and methodology based on calculation of time delays between nearby sensors, giving an estimation of slowness vector for the wavefront propagating through the array. This type of methodology has been used by several authors and applied to various volcanoes (e.g., Saccorotti and Del Pezzo, 2000; Almendros et al., 2001a; Métaxian et al., 2002; Rocca et al., 2004; Inza et al., 2011, 2014).

We present in this work results of the analysis of a phreatic eruption that occurred in April 2014, based on the comparison between the estimated and modeled slowness vector and a slowness vector model. In what follows, we first outline the recent activity of Merapi volcano, including phreatic eruptions in April 2014 (Sections 2 and $3)$. Next, we describe the seismic networks and provide the details about the characteristics of recorded seismic signals corresponding to the eruption, including a description of different seismic phases, in time and frequency (Section 4). In Section 5, we derive a shallow velocity structure of Pasar Bubar area from a local array analysis based on the SPAC method (Aki, 1957). Section 6 details the April 20th eruption by analyzing recorded seismic signals using different methodologies: polarization analysis (Section 6.1), high-frequency transient events source location (Section 6.2) and low-frequency source tracking by dense array analysis (Section 6.3). Results show that the seismic activity that was $1-2 \mathrm{~km}$ below the crater to the south at the beginning of eruption, rose up to the dome at an estimated speed of $10 \mathrm{~m} / \mathrm{s}$. The results are discussed in details in Section 7.

\section{Recent activity of Merapi volcano}

The October-November 2010 eruption was the largest eruption in more than 100 years (Jousset et al., 2013). It was characterized by extruding lava domes with a rate of up to $35 \mathrm{~m}^{3} / \mathrm{s}$, vertical eruptive columns of up to $17 \mathrm{~km}$ altitude and pyroclastic flows that extended up to $16 \mathrm{~km}$ on the south flank. This eruption was unusual compared to typical eruptions of Merapi in 20th century characterized by the production of summit lava domes which collapse and produce blocks and ash pyroclastic flows. Known as Merapi-type, pyroclastic density currents usually reach horizontal distances of around $5 \mathrm{~km}$. The 2010 eruption was approximately 10 times larger and more explosive than eruptions of the previous decades, similar to the 1872 eruption (Jousset et al., 2013). Although less frequent than effusive eruptions, explosive eruptions appear to be characteristic of the activity of Merapi volcano. The 2010 eruption created a new crater $400 \times 300$ m wide and 150-200 $\mathrm{m}$ deep with a resurgent dome in its center (Komorowski et al., 2013). Walter et al. (2015) estimated that the dome reached diameters of $190-220 \mathrm{~m}$ with a plateau-like surface area of about $40,000 \mathrm{~m}^{2}$. The Merapi volcano went through a period of quiescence between November 2010 and August 2012. A dozen phreatic eruptions of various energy identified by visual and/or seismic observations took place between August 2012 and April 2014. One of the most powerful occurred on November 18th 2013. Based on high resolution TerraSAR-X satellite radar imagery, Walter et al. (2015) determined that the November eruption formed a major fracture cutting the complete dome structure. The fracture was estimated to be $200 \mathrm{~m}$ long and up to $40 \mathrm{~m}$ wide, oriented in a NNW-SE direction. The following eruptions have slightly widened the fracture. Explosive activity stopped in April 2014. No more phreatic eruptions have occurred between April 2014 and May 2018. Merapi experienced a new series of phreatic eruptions in May-June 2018 followed by a magmatic eruption that started in August 2018.

\section{Phreatic eruptions of April 20th}

The eruption of April 20th occurred at 4:26 a.m. local time (April 19th, 21:26 UTC). It was visually observed from the Sewukan village, District Shaman, but not from the observation posts due to cloud cover. Thin ash deposits were observed in the areas east, south and southwest of Merapi extending to a distance of $15 \mathrm{~km}$. The sound of eruption was heard up to 6-7 km away from the volcano. Visual observations of the crater made two days after the eruption by the monitoring team of BPPTKG reported: 1) the fracture located in the center dome expanded from 40 to $70 \mathrm{~m}, 2$ ) the presence of significant oxidation of rocks (color red) visible on the west wall of the fracture, 3 ) a large number of new blocks on the western side of the dome, but no new block on the east side (Fig. 1).

\section{Data}

The monitoring system of Merapi is operated by the CVGHM (Center of Volcanology and Geological Hazard Mitigation). Most of the geophysical network was destroyed by 2010 eruption (Budi-Santoso et al., 2013). The new monitoring network, installed from 2011, consists of seventeen seismic stations (broadband and short-period), among which stations provided by DOMERAPI project, including a small aperture seismic array.

\subsection{Seismic networks}

In this study, we used seismic stations belonging to different networks for studying the shallow velocity structure and for different analysis of the April 20th eruption (Fig. 2): 


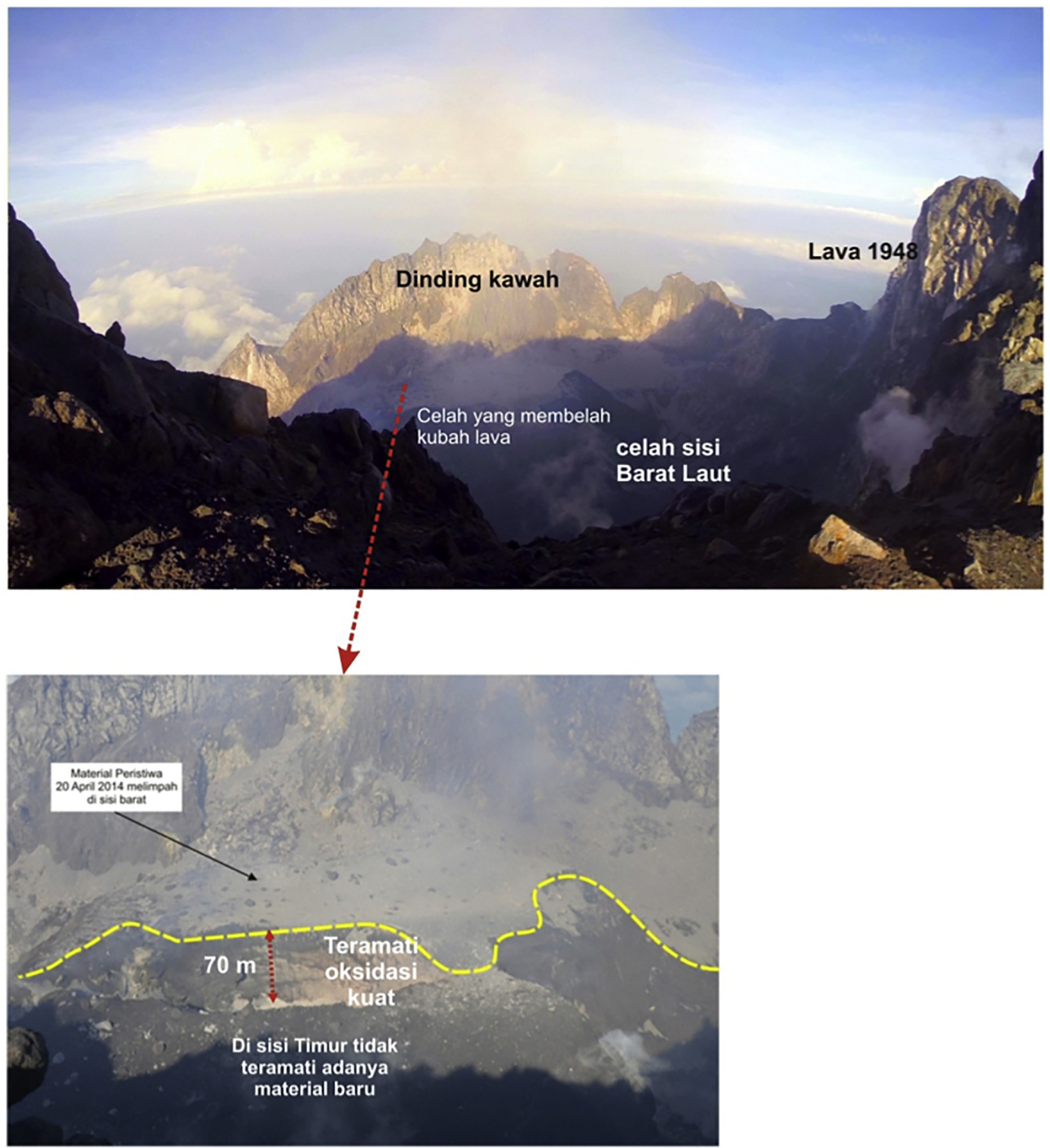

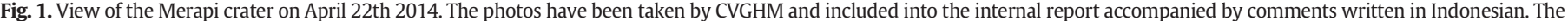

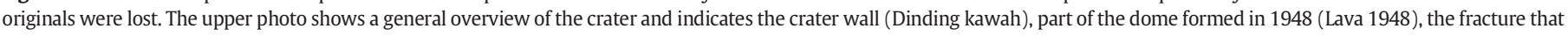

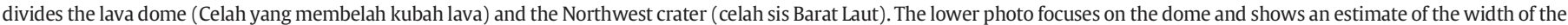

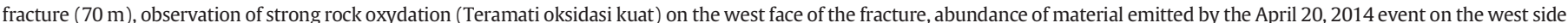

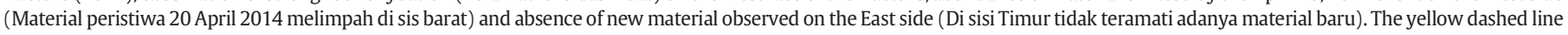
highlights the western part of the crater covered with deposits (grey ash and blocks of rock) of the eruption.

1) We performed temporary small-aperture array measurements of seismic noise at Pasar Bubar (blue points in Fig. 2 bottom) in order to estimate shallow Vp and Vs velocity structure. Pasar Bubar is the closest site to the summit with a more or less smooth topography. We used 7 Guralp-6TD stations. The stations were arranged in a 6 branches star-shape array with a permanent station in the center and 6 stations disposed every $60^{\circ}$. These stations were positioned at distances of $5,10,20,40,80,120$ and $215 \mathrm{~m}$ from the center. The last value being the maximum distance permitted given the sharp topography near the summit (Fig. 2 bottom). Seismic noise has been recorded for each radius for a period of 1 to several hours.

2) A seismic network with an aperture of $60 \mathrm{~km}$ and composed of 46 stations centered on Merapi which has been operational between October 2013 and April 2015 through the French-Indonesian 

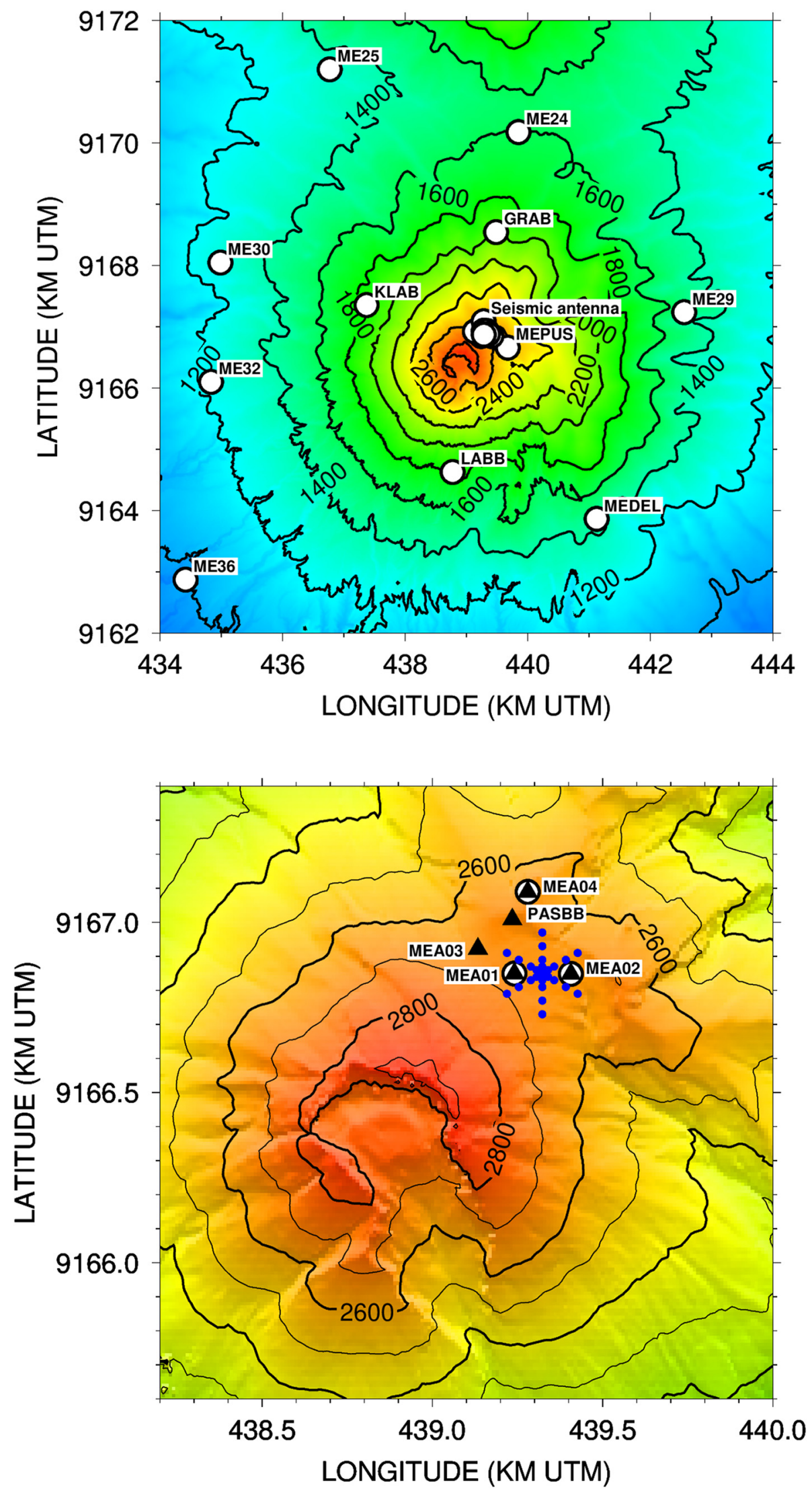

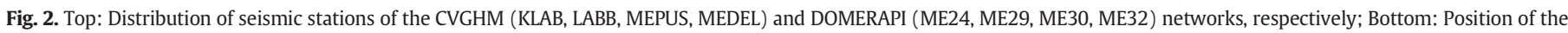

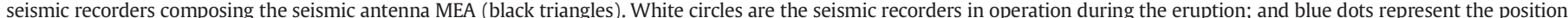

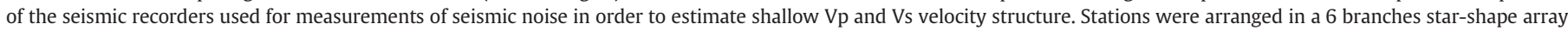

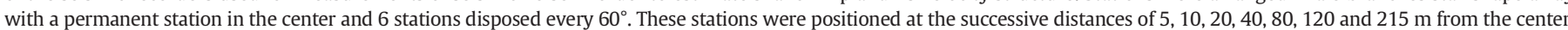


collaborative project DOMERAPI for a tomography study of Merapi Volcano (Widiyantoro et al., 2018). The eruption was recorded by the closest stations of this network (ME24, ME25, ME29, ME30, ME32). These stations were used for high frequency transient events source location.

3) A small aperture array composed of 4 stations installed close to the summit on the site of Pasar Bubar in November 2013. This network called MEA (MErapi Antenna, stations MEA01 to MEA04) has an aperture of $280 \mathrm{~m}$ (Fig. 2 bottom). The shortest distance between sensors is $120 \mathrm{~m}$ and the longest $280 \mathrm{~m}$. The MEA network is composed of Guralp CMG-6TD stations. Sensors have a flat response characteristics from $30 \mathrm{~s}$ to the Nyquist frequency $(50 \mathrm{~Hz})$. Station altitudes vary between $2662 \mathrm{~m}$ and $2688 \mathrm{~m}$. For the first months of 2014 we faced several technical problems mainly due to heavy rains. Only 3 stations (MEA01, MEA02 and MEA04) were functioning at the time of April 20th eruption. They were used for the slowness vector and polarization analysis.

4.2. Phreatic eruption seismic signal

The April 20th eruption started with a series of small high frequency signals (1280-1400 s in Fig. 3. The time in seconds is referenced to April 19th 21:00 UTC). The seismic signal amplitude increases in two main increment periods, one around $1430 \mathrm{~s}$ and the other around $1600 \mathrm{~s}$. The total duration of the recorded eruptive event is $25 \mathrm{~min}$. The section of the signal of greater amplitude lasts for about $5 \mathrm{~min}$ and is characterized by a spectral distribution ranging from $0.3 \mathrm{~Hz}$ to over $20 \mathrm{~Hz}$ (Fig. 3 right). The coda lasts approximately $15 \mathrm{~min}$ and includes small transient individual events. This seismic signal generated by the eruption denotes a complex process.

We can discriminate 3 main stages shown in Fig. 3: I) 1270 to 1430 s, several small high-frequency micro-earthquakes. These microearthquakes have an emergent onset with indistinct $\mathrm{P}$ or $\mathrm{S}$ waves and dominant frequencies in the range 1-40 Hz, II) 1430 to $1580 \mathrm{~s}$, tremor with a relatively low-frequency phase starting from $0.3 \mathrm{~Hz}$ and higher amplitudes compared to the previous phase, III) $1580 \mathrm{~s}$ to the end of the signal (around $2700 \mathrm{~s}$ ): the longest phase, characterized by an increase of the amplitude in the beginning and a progressive decrease after about $300 \mathrm{~s}$ of duration. It is also composed of low frequencies $\leq 5 \mathrm{~Hz}$, similar to phase II, but is characterized by more energy at high frequencies. The highest amplitude part has predominantly highfrequency content. A local event occurs at the end of the eruption $(2170 \mathrm{~s})$. The signal corresponding to the eruption was recorded as far as $10 \mathrm{~km}$ from the vent.

Our main objective is to track the source position during the eruptive process and delineate the seismogenic zones corresponding to the different phases of the eruption. To get to that point, we locate the small high-frequency transient events $(1-30 \mathrm{~Hz})$ of the first stage by using a network-based time-delay approach. Then, we analyze the signal polarization and locate the source of low-frequency part of the signal by performing a slowness analysis. Source location methodologies relies on the knowledge of velocity structure which we will discuss first.

\section{Shallow velocity structure at Merapi}

The shallow velocity structure at Merapi has been previously studied by Lühr et al. (1998) and Wegler and Luhr (2001) by using an active seismic experiment. They used $3 \mathrm{~km}$-long seismic profiles of short period seismometers located respectively South, North-West and NorthEast of the dome. The experiment concentrated on the heterogeneous shallow velocity structure of Merapi within a radius of $5 \mathrm{~km}$ from the active dome. The recorded signals were strongly affected by multiple scattering due to the strong heterogeneity of the medium. They proposed the existence of a near-surface low-velocity layer, where P-wave velocity increases from about 0.8 to $2.8 \mathrm{~km} / \mathrm{s}$ within the first $200 \mathrm{~m}$ in depth.

Determining the shallow velocity structure at Merapi is challenging because it consists of pyroclastic flows deposits, block-and-ash flow deposits as well as lava flows (Gertisser et al., 2012). The vertical component of the seismic noise recorded by the temporary small-aperture array at Pasar Bubar has been analyzed by using the SPAC method in order to determine Rayleigh phase velocity dispersion curves. We used the Geopsy software package (Wathelet et al., 2005; Köhler et al., 2007) and calculated for each array configuration (each radius) crosscorrelation functions for all pairs of stations and their azimuthal average, which provided a Bessel function depending on the frequency and the phase velocity. Using the analysis performed with the 7 different configurations of array with radius varying between 5 and $215 \mathrm{~m}$, we obtained phase velocities for frequencies between 0.6 and $20 \mathrm{~Hz}$. The dispersion curve and the fit obtained for the fundamental mode of Rayleigh waves with geopsy software is shown in Fig. 4. The inversion was completed using Dinver software (Wathelet, 2008) implemented in Geopsy software to obtain a 1D Vs velocity model showed in Fig. 5. Results reveal several layers with strong velocity changes mainly at about $60 \mathrm{~m}, 120 \mathrm{~m}$ and $360 \mathrm{~m}$ below the surface taken at an altitude of $2700 \mathrm{~m}$. In the superficial layer, $V_{p}$ is varying between 750 and $970 \mathrm{~m} / \mathrm{s}$, reaching $1870 \mathrm{~m} / \mathrm{s}$ at $120 \mathrm{~m}, 2570 \mathrm{~m} / \mathrm{s}$ at $360 \mathrm{~m}$ depth. The last value of our velocity model is $3200 \mathrm{~m} / \mathrm{s}$ at $450 \mathrm{~m}$ depth. Based on structural information available for several andesitic and basaltic volcanoes, Lesage et al. (2018) proposed a generic model that can describe the variations of P- and S-wave velocities in the first $500 \mathrm{~m}$. They suggested a power law function depending of depth $(\mathrm{z})$ the surface velocity $V_{0}$ and 2 coefficients $\alpha$ and $a$ :

$V(z)=V_{0}\left[(z+a)^{\alpha}-a^{\alpha}+1\right]$

We have represented this model in Fig. 5 after having modified the coefficients of the expression given by Lesage et al. (2018) for adjusting the curve to the model obtained for Merapi and extrapolating it in depth. The coefficients for $\mathrm{P}$ and $\mathrm{S}$ waves are respectively: $V_{0} p=$ $650 \mathrm{~m} / \mathrm{s}, \alpha_{p}=0.27, a_{p}=10$ and $V_{0} s=360 \mathrm{~m} / \mathrm{s}, \alpha_{s}=0.30, a_{s}=18$ for the first $500 \mathrm{~m}$ and $V_{0} p=1500 \mathrm{~m} / \mathrm{s}, \alpha_{p}=0.144, a_{p}=15$ and $V_{0} s=830 \mathrm{~m} / \mathrm{s}$, $\alpha_{s}=0.17, a_{s}=22.5$ for depth between $500 \mathrm{~m}$ and $10 \mathrm{~km}$. This construction of the velocity model in two parts allows to take into account the results obtained with the SPAC analysis for the very superficial structure and the results of the seismic tomography study made by Widiyantoro et al. (2018) for the deeper structure. This velocity model is considered in the following analysis.

\section{Analysis of the eruption of April 20th}

\subsection{Polarization analysis}

Polarization attributes are determined through a time-frequency decomposition (Stockwell et al., 1996) and a polarization analysis based on Pinnegar (2006). By considering the signal as a superposition of elliptical motions, the idea of Pinnegar (2006) is to directly relate the Fourier spectra (and thus the Stockwell coefficients) to an elliptical motion parameterization. The polarization attributes used in this study to characterize the elliptical motion are ellipticity and orientation of the major displacement calculated through estimation of the trend (azimuth calculated from the North) and a plunge angle, as described in Labonne et al. (2016). Note that the Stockwell transform window is a scalable Gaussian window with a frequency range defined as an interval where its standard deviation equals one period length. Based on that principle, we use in this study a Stockwell-like transform with a standard deviation that is equal to the three periods length meaning three full lapses of the ellipse. Seismic signals from 3-component station MEA01 is analyzed.

We describe below the most striking results of the polarization analysis. Low ellipticity values, around 0.2 , between 1420 and 1570 s, corresponding to Phase II, indicate a linearly polarized wavefield, which is consistent with body waves (Fig. 6a,b). In the same time window, trend values of about 30 modulo 180 (Fig. 6c,d) are aligned with the direction of the crater (back-azimuth $210^{\circ}$ ). These results suggest P or SV waves. 

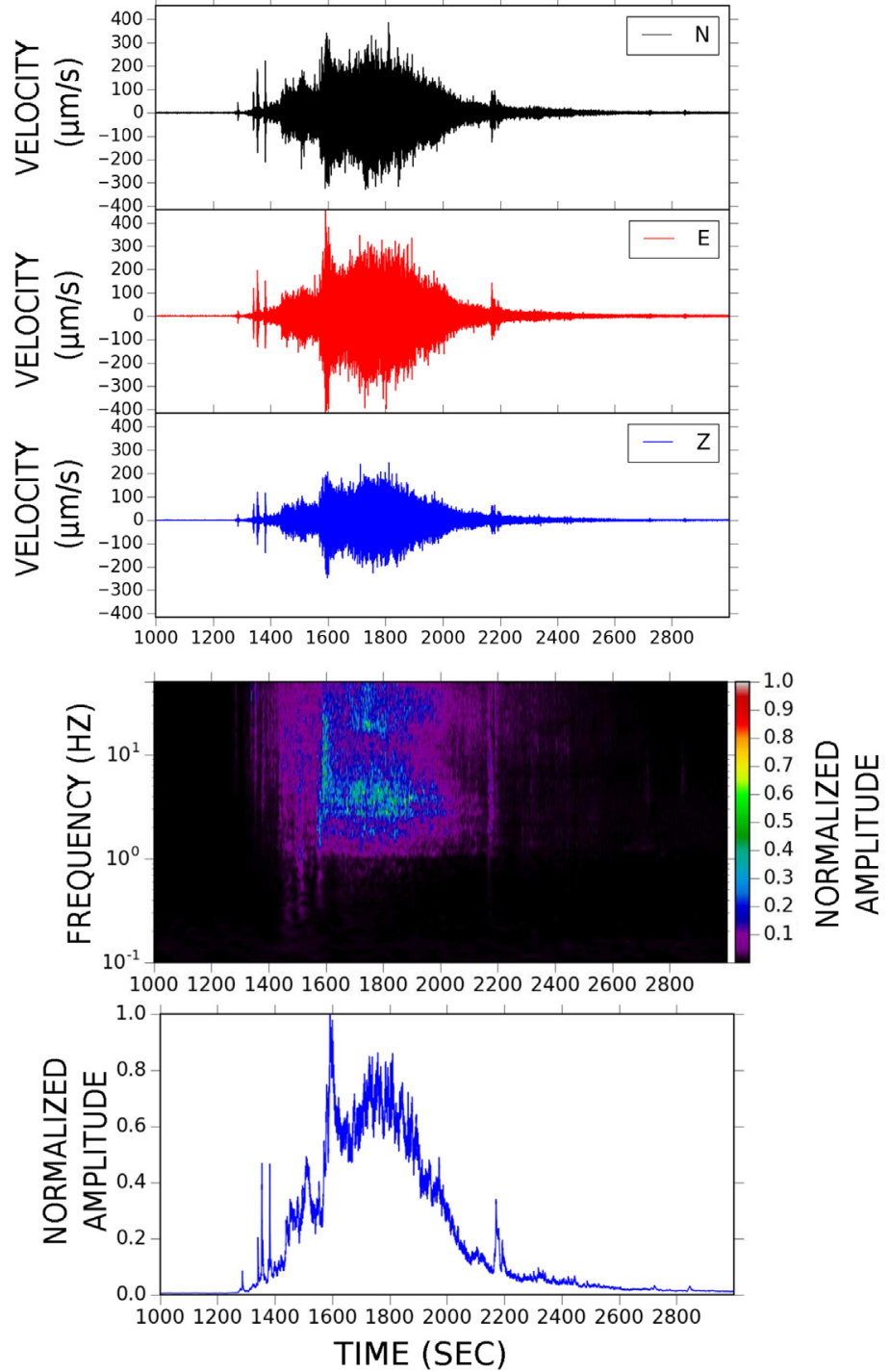
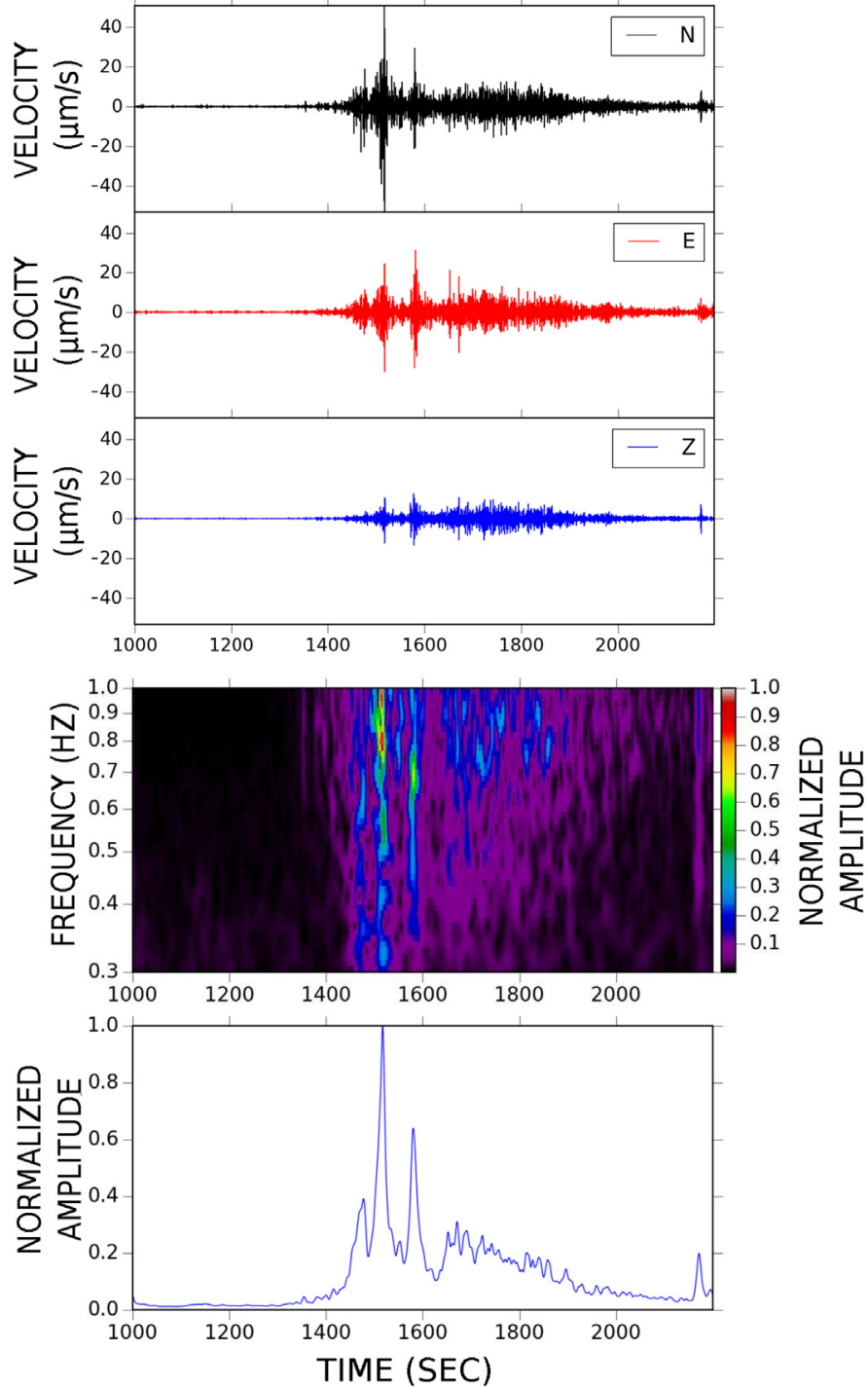

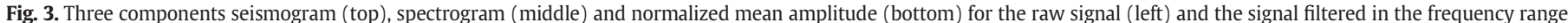

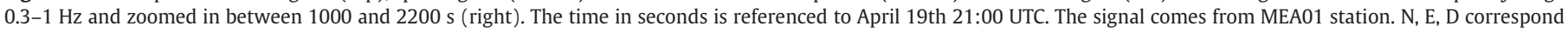

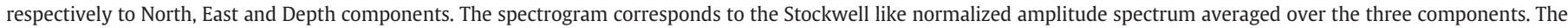
normalized mean amplitude is simply a different representation of the amplitude as a function of time (average of each column of the above spectrogram).

Finally, plunge values are very low, around 5-10 $0^{\circ}$ (Fig. 6e,f), which is consistent with P waves coming from the surface or SV waves arriving almost vertically. Ray tracing performed with the 1D P-velocity model defined previously taking into account the topography (see Section 5) gives an incident angle for a superficial source around $40^{\circ}$ and therefore a plunge value of $50^{\circ}$, inconsistent with our result. On the contrary, ray tracing performed with the $S$ velocity model for a source at $1500 \mathrm{~m}$ below the surface gives an incident angle and a plunge value of $8^{\circ}$, which is coherent with the observation. We can therefore conclude that waves composing Phase II are dominated by SV waves. This is also consistent with the study of Merapi structure performed by Wegler and Luhr (2001) using an active seismic experiment that found a dominance of horizontal wavefield components. They interpreted this observation as $\mathrm{S}$ waves arriving almost vertically due to the near-surface low-velocity layer. Higher values of ellipticity after $1600 \mathrm{~s}$ and until the end of the event indicate a higher content of surface waves.

\subsection{High frequency transient events source location}

High frequency transient events appearing at the beginning of eruption are characterized by emergent onsets with $\mathrm{P}$ - and S-wave arrivals that are difficult to detect (Fig. 3). This prevents the use of traditional phase picking-based localization methods for estimating the spacetime location of these events. We applied here a methodology developed by Poiata et al. (2016) and designed for the detection and location of seismic sources associated with low signal-to-noise ratio. The methodology consists of two major steps: 1) extracting from the signal recorded at each station its frequency-dependent statistical features by means of higher-order statistics transform (kurtosis), and providing simplified broadband representation of the signal - characteristic functions (CF);2) simultaneous detection and location of a potential event, exploiting the network coherence of $\mathrm{CF}$ features and based on summation of station-pair time-delay estimate functions projected onto 3D spatial grids of theoretical travel-time differences calculated for an assumed velocity model (Poiata et al., 2016). The station-pair time-delay functions are calculated by cross-correlations of stationspecific CFs. The analysis of continuous data recorded at network stations is performed in a sliding time-window, providing for each timewindow a 3D map (imaging function), corresponding to the likelihood of source location in space and time. For our application the theoretical $\mathrm{P}$ - or S-wave travel-times for each station were calculated with the Grid2Time routine of NonLinLoc (Lomax, 2005, 2008), assuming a 20 


\section{Fundamental mode}

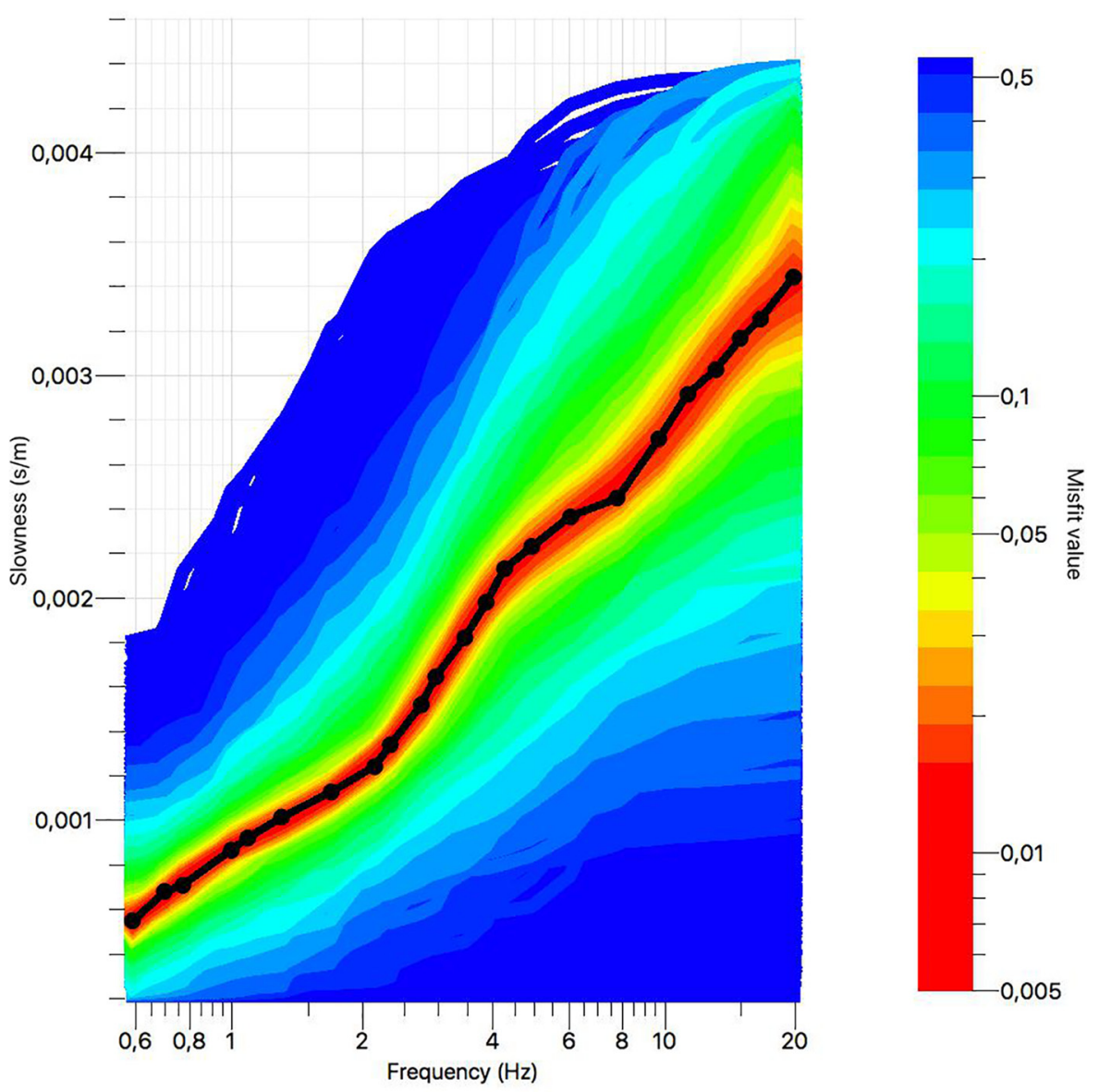

Fig. 4. Dispersion curve and the corresponding fit obtained for the fundamental mode of Rayleigh waves with geopsy software.

$\times 20 \times 10 \mathrm{~km}$ grid (with a spacing of $0.1 \mathrm{~km}$ ) centered on Merapi and using the velocity model obtained in the previous section. Data analysis was performed with the BackTrackBB program available from GitHub repository: https://github.com/BackTrackBB.

We analyzed 2000 second-long seismic signals, recorded at 9 stations and including the eruption stage, with a sliding time window of 10 second and 2 second shift between the consecutive time-windows. In Fig. 7a we present the processed raw signal and the final broadband (1-40 Hz) kurtosis CF (convolved with the Gaussian filter to account for timing uncertainties of phase arrival) for a selected station recording. For more details, the reader is referred to Poiata et al. (2016). The resulting final CFs (blue line in Fig. 7a) calculated for all network stations were further used for estimating the location of transient events. We could detect and locate five events during the Phase I assuming a trigger threshold of 0.9 for the 3D normalized imaging function. The summary of analysis including the waveforms and the CFs for the processed time-windows from 9 stations as well as the likelihood imaging function for the first detected and located event are shown in Fig. 7b and $\mathrm{c}$. The locations of the 5 detected high-frequency transient events is less than $300 \mathrm{~m}$ from the crater rim and $1400-2000 \mathrm{~m}$ beneath the dome ( $700-1300 \mathrm{~m}$ ASL). Two additional events belonging to the beginning of the tremor of Phase II are detected and located at $1300 \mathrm{~m}$ and $1600 \mathrm{~m}$ ASL, respectively. These 2 events were located with the 6 stations closest to the crater offering a better constrained location. Based on the results obtained from the polarization analysis in the previous sections, we located events belonging to Phase I assuming the P-wave as being a predominant phase, as S-wave was used for the events in Phase II. The depth distribution of the located events is presented in the cross-section in Fig. 9d. Error bars were estimated by taking half width of the maximum of the normalized PDF of the source position at the value at 0.9 .

\subsection{Source tracking by dense array analysis}

We focus here on tracking the positions of the source of lowfrequency tremor during the whole eruptive process and to delineate horizontally and vertically seismogenic zones, corresponding to the different eruption phases. The analysis consists of: 1) an estimation of slowness vector and evaluation of the back-azimuth and the apparent slowness (or velocity) for successive time windows along the seismograms recorded by the MEA array; 2) calculation of a slowness vector model for a volume that includes the crater area and reaches several kilometers in depth in order to include the conduit area. We take into account the topography and use the $1 \mathrm{D}$ velocity model; 3 ) Comparison between the model and the observations for determining the source positions with a probabilistic approach. This strategy has already been applied in a number of studies. Almendros et al. (2001a, 2001b) used a slowness vector model obtained from frequency-slowness analysis of synthetic signals generated using a finite-difference method and including the effects of topography as well a considering a 3D velocity model. Synthetic seismograms were computed for a set of sources distributed over a uniformly spaced 3D grid, for each sensor of the seismic arrays. The authors applied this methodology to long-period (LP) events and tremors recorded at Kilauea Volcano with 3 dense seismic arrays. Rocca et al. (2004) applied a slightly different approach; the predicted slowness vectors were not calculated from the synthetic seismograms, but by applying directly finite-differences ray tracing in a 3D velocity structure. This approach is a priori lighter in terms of computation 


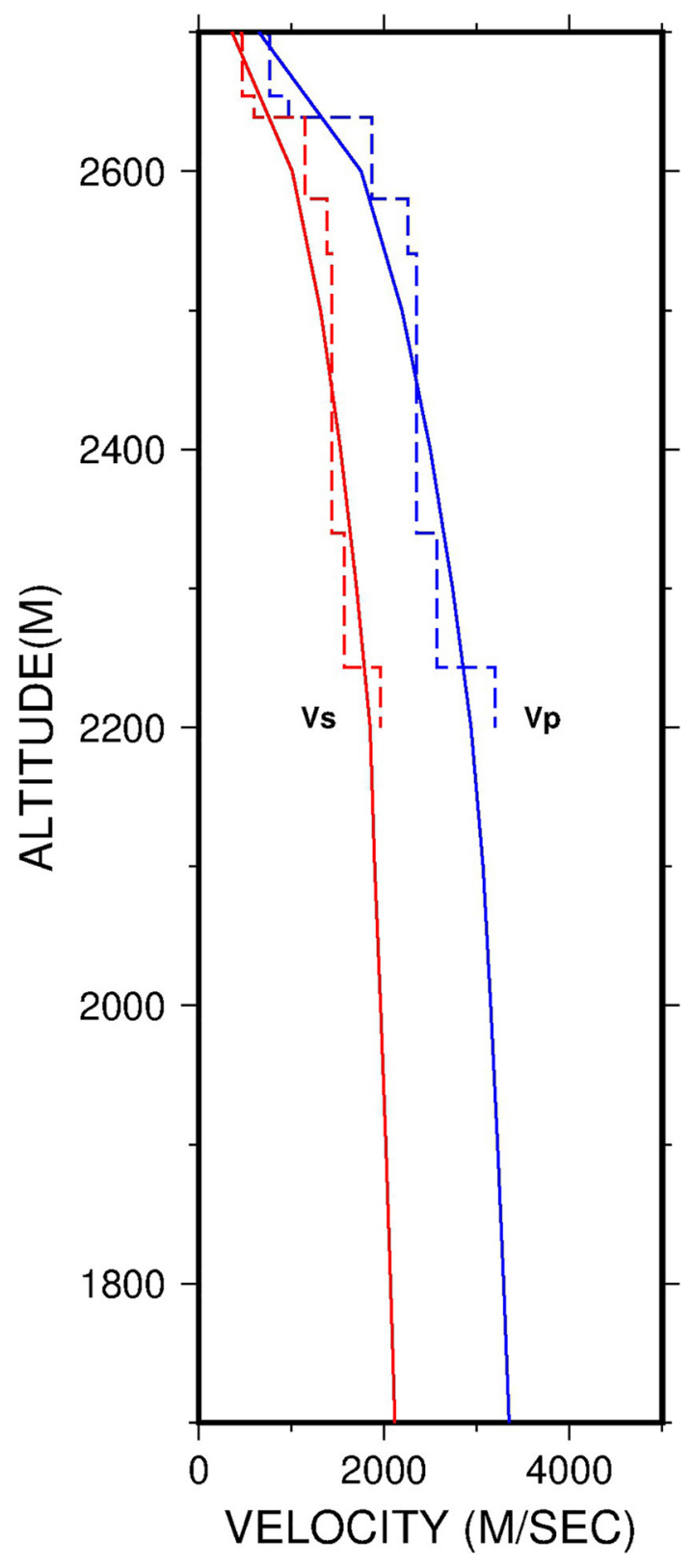

Fig. 5. 1D velocity model, Vp in blue and Vs in red. Dashed lines represent the model obtained with the SPAC method and the inversion of Rayleigh phase velocity dispersion curves. Thin full lines represent the generic model proposed by Lesage et al. (2018) for andesitic and basaltic volcanoes after modification of the parameters. The coefficients for $P$ and $S$ waves are respectively: $V_{0} p=650 \mathrm{~m} / \mathrm{s}, \alpha_{p}=0.28, a_{p}=10$ and $V_{0} s=320 \mathrm{~m} / \mathrm{s}, \alpha_{s}=$ $0.32, a_{s}=15$.

resources and very similar to what we are doing in this work. Both approaches use of the horizontal components of the slowness vector.

\subsubsection{Slowness vector estimation}

We estimate the slowness vector by solving following equation:

$\tau_{i j}=\mathbf{S} \cdot \mathbf{r}_{i j}$

where the dot denotes the notation of scalar product, $\tau_{i j}$ and $\mathbf{r}_{i j}$ are respectively the time delay and the relative position vector between seismometers i and $\mathrm{j}, \mathbf{S}=(-s \sin \theta,-s \cos \theta)$ is the slowness vector, $\theta$ is the back-azimuth, measured clockwise from the north. Time delays are calculated for each pair of seismometers in successive time-windows moving along the recorded seismograms by applying the cross- spectral method (Jenkins and Watts, 1998; Poupinet et al., 1984; Frechet, 1985; Got et al., 1994). After several tests, the length of the moving window was fixed to $40 \mathrm{~s}$ with an overlap of $80 \%$. Given a set of time delays $\tau_{i j}$ and associated errors $\sigma_{\tau_{i j}}$ calculated from the variance in the estimate of the cross-spectrum phase, the corresponding slowness vectors $\mathbf{S}$ can be recovered by inversion, assuming that 1 ) the wave field is composed by non-dispersive plane waves, 2 ) only one wave propagates across the array or one is dominant in a given signal window and 3) the medium beneath the array is laterally homogeneous so that slowness vectors and corresponding errors are estimated by a linear inversion (standard least squares) of the time delays using equations (43) and (44), respectively, of Tarantola and Valette (1982) for the linear inversion and the calculation of the a posteriori covariance (Métaxian et al., 2002). The plane wave hypothesis is true when array dimensions are small compared to the distance between the array and the source. Almendros et al. (1999) expressed the relation between the time delays and the slowness vector in the case of spherical waves. They showed that source location is more accurate using the circular wave theory for epicentral distances smaller than about 3 times the array aperture. MEA aperture is $280 \mathrm{~m}$. If we hypothesize that the eruption is generated into the superficial part of the conduit, the corresponding epicentral distance is 2.7 times MEA aperture. Indeed, the distance between the center of the dome surface and the center of MEA is $\sim 750 \mathrm{~m}$. Altitudes of MEA and the top of the dome are approximately the same. Thus, we are very close to the conditions required for the applicability of the plane wave assumption.

The back-azimuth and the apparent velocity are derived from the horizonthal components of the slowness vector of each time-window. The expression of the back-azimuth is given by:

$\theta=\arctan \left(\frac{S_{x}}{S_{y}}\right)$

Apparent slowness, also called ray parameter, is expressed by:

$S_{a p p}=\sqrt{S_{x}^{2}+S_{y}^{2}}$

The back-azimuth is defined by the angle of the wavefront that arrives at the antenna, measured clockwise between north and the direction towards the epicenter in the horizontal plane.

\subsubsection{Slowness vector model}

We have an a priori knowledge of the eruptive emission zone corresponding to the dome fracture defined by Walter et al. (2015). We are looking for estimating the hypocenter of the eruption triggering phase and the time evolution of the source depth in conduit during the whole process. To simplify the problem, we considered a vertical distribution of sources spaced by $100 \mathrm{~m}$ beneath the dome and we performed ray tracing between each hypothetical source and the center of the antenna taking into account the topography and the 1D S-wave velocity model determined in Section 5. We hypothesize that the wavefield is dominated by S-waves during Phase I and by surface waves during Phase III. The travel-times are computed using the finite-difference code solving the eikonal equation developed by Podvin and Lecomte (1991) and adapted by Monteiller et al. (2005). In this adaptation, a posteriori ray tracing is performed by computing the travel-time field gradient, and travel time derivatives allowing the accuracy reaching $10^{-4} \mathrm{~s}$. The slowness values are deduced from the coordinates of the ray calculated for the last 2 points. The last point is placed at the surface, in the center of the MEA antenna. We derive a slowness vector model which is composed of slowness vectors calculated for each depth point. Source depth is related to the apparent slowness whose value decreases with depth. The resulted model can also represented in apparent velocity as function of source depth (Fig. 8). 

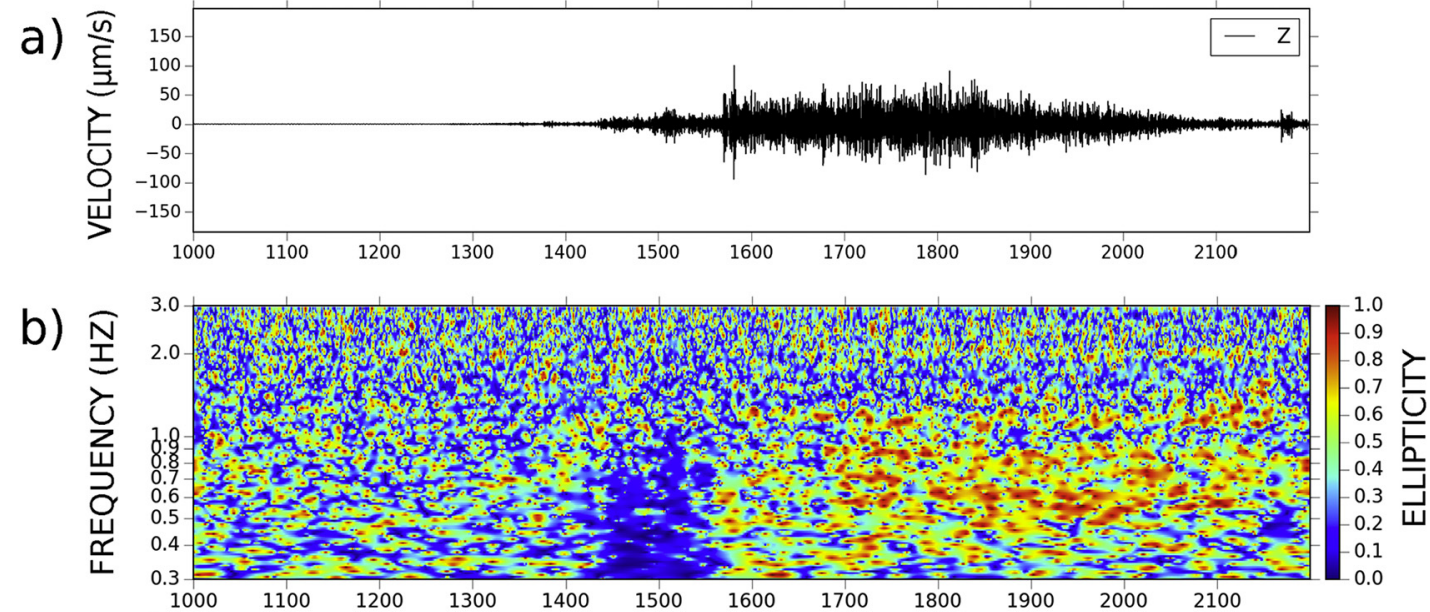

C)

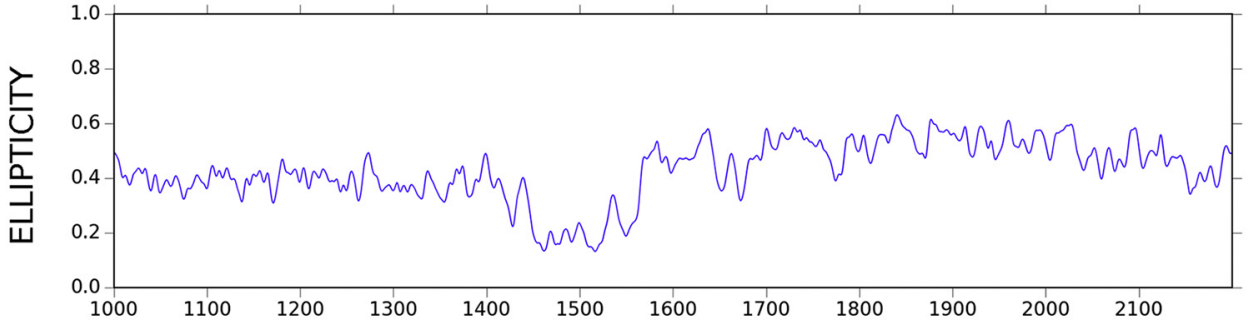

d)

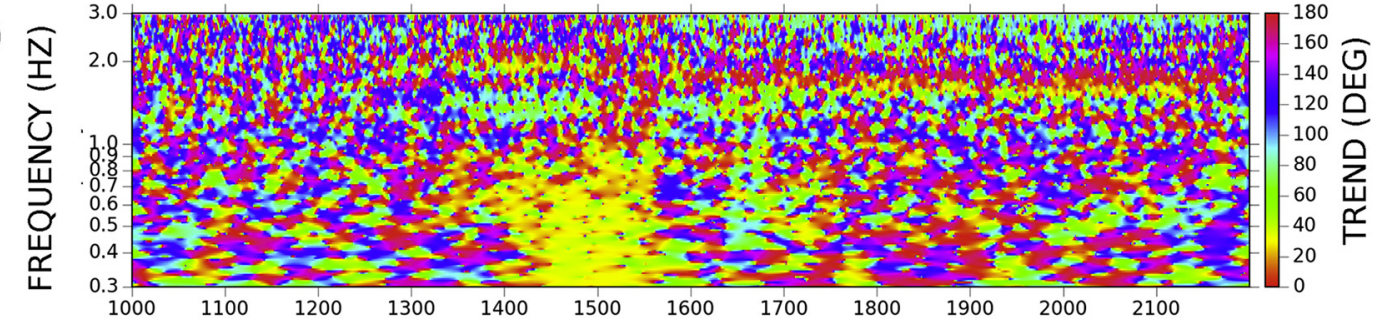

e)
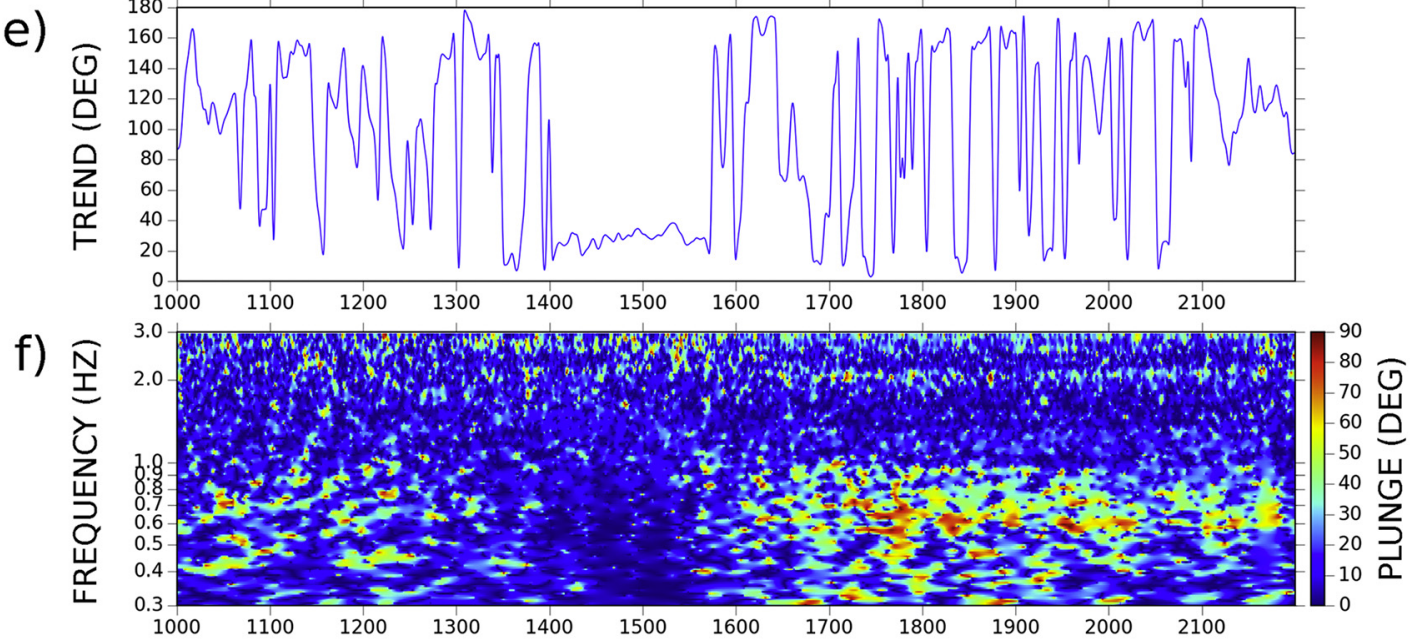

g)

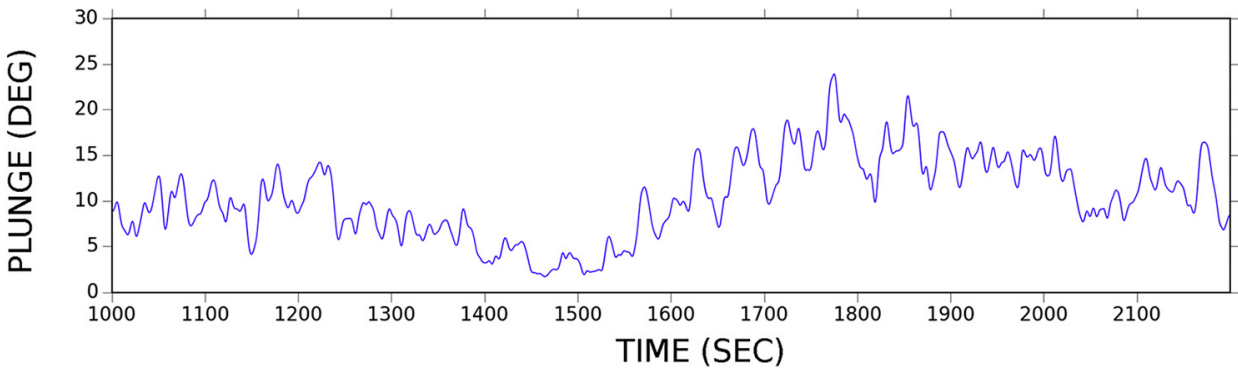

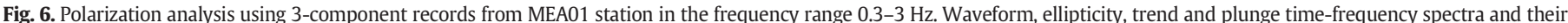

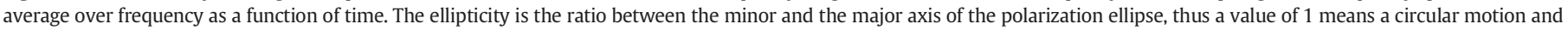
0 a linear motion. The trend and the plunge correspond respectively to the azimuth from the north and to the inclination from horizontal of the major axis. 


\subsubsection{Source depth estimation}

We then compare the observed values of the apparent slowness with those of the model for signal time-window with the azimuth pointing to the crater area. We limit the analysis to back-azimuth values in the range of $190^{\circ}-235^{\circ}$ because we expect little lateral variations of the apparent slowness across the crater for a given depth. Then, for each selected time-window centered at time $t$, a probability density function (PDF) of the apparent slowness is computed:

$\rho_{s}(z) \propto \exp \frac{-\left(s^{o b s}-s_{z}^{c a l}\right)^{2}}{2 \sigma^{2}}$

where $s^{o b s}$ is the apparent slowness observation at MEA and $s_{z}^{c a l}$ is the apparent slowness calculated with the model at depth z. $\sigma$ is the uncertainty on the apparent slowness.

\subsubsection{Results}

We analyzed the signals in two frequency bands, $0.3-1 \mathrm{~Hz}$ and 1-3 Hz to take into account on one hand, the lowest frequency component of the signal and, on the other hand, include the main peaks of the spectrum around $2 \mathrm{~Hz}$ (Fig. 3). The geometry of the antenna does not allow to analyze signals beyond $3 \mathrm{~Hz}$ due to the risk of aliasing. The time-delays were calculated using a sliding time-window applied to the records from the 3 stations that operated during this event: MEA01, MEA02 and MEA04. Different time-window widths in the range of 2.5-40 s were tested with an overlap of $80 \%$. Longer timewindows generally provide smoother results making them more stable and reliable. We solved the Eq. (1) for obtaining the horizontal components of slowness vector, from which we deduced the back-azimuth and the apparent slowness (Eqs. (2) and (3)).

The final results are shown in Fig. 9 for a 40-second-long timewindow moved with an increment of $5 \mathrm{~s}$. Each of the presented values is associated to the first point of the corresponding time-window. Blue and black points correspond respectively to the frequency bands $0.3-1 \mathrm{~Hz}$ and $1-3 \mathrm{~Hz}$. One hour of non-filtered signal including the eruption is represented in Fig. 9a. Fig. 9b-d shows the results of the slowness vector analysis from $20 \mathrm{~min}$ before, during and after the eruption. The coherency averaged over the three pairs of stations (Fig. 9b) obviously has higher values in the lower frequency band. Nevertheless, similarities are observed during the eruptive phase in the 2 frequency bands. In the $0.3-1 \mathrm{~Hz}$ frequency band, seismic noise is dominated by the ocean swell, which explains the very high values of the average coherency before and after the eruption. Coherence estimated for the eruptive signal is slightly lower compared to that of the noise but, still remains high. The maximum amplitude of the seismic noise recorded before the eruption is $0.6 \mu \mathrm{m} / \mathrm{s}$ in the frequency band $0.3-1 \mathrm{~Hz}$. By comparison, the maximum amplitude of the eruptive signal is respectively $250 \mu \mathrm{m} / \mathrm{s}$ and $19 \mu \mathrm{m} / \mathrm{s}$ for non-filtered and filtered signal in the frequency band $0.3-1 \mathrm{~Hz}$. Consequently, high coherency values observed during the eruptive process in the frequency band $0.3-1 \mathrm{~Hz}$ are most likely resulting from volcanic sources. The average coherency obtained in the frequency band $1-3 \mathrm{~Hz}$ (black points) denotes a sudden increase at $1280 \mathrm{~s}$ (vertical dotted line). This time also represents the beginning of the period for which the values of the slowness vector stabilize as shown in Fig. 9c,d. Back-azimuth and apparent velocity values exhibit a strong dispersion before and after the eruption in both frequency bands (Fig. 9c,d). We consider it as the beginning of the eruptive process. It also corresponds to the occurrence of the first high-frequency transient (Fig. 9a).

The aperture of the array is too small in far-field conditions for analyzing the ocean swell signal, which explains the variability of the slowness vector estimations observed before the eruption starts. On the contrary, the eruptive source located very close to the array provides remarkably stable values of slowness vector. Slowness values are relatively stable during the eruption period, with clear temporal evolution which are quite similar in both frequency bands. Back-azimuth values indicate that sources are located in the crater area. They oscillate mainly around $190^{\circ}-235^{\circ}$, which correspond to the back-azimuth limits of the dome fracture seen from the barycenter of the antenna. This range of values is represented by the horizontal grey band in Fig. 9c. Note that the back-azimuth values are partially outside this band during the second part of the eruption in the frequency band $1-3 \mathrm{~Hz}$. The apparent velocity has quite similar values in both frequency bands, except at the very beginning of the eruption and at the end. The apparent velocity decreases at the beginning of the event, then stabilizes, increases again and finally decrease reaching lower values in agreement with surface sources (Fig. 9d).

We saw in Section 6.1 that the wavefield is polarized only in the frequency band $(0.3-1 \mathrm{~Hz})$. Array analysis shows quite similar results for both frequency bands and we observed that the influence of ocean swell during the eruptive phase is probably negligible since the amplitude of the eruptive signal is significantly higher compared to the seismic noise preceding the eruption. In the following, we therefore focus on the analysis of the eruption in the frequency band $(0.3-1 \mathrm{~Hz})$.

Results for different phases are detailed in Fig. 10. Back-azimuth values oscillate between $200^{\circ}$ and $235^{\circ}$ during the first part of Phase I, then decrease to $200^{\circ}$. Back-azimuth reaches its minimum value of $200^{\circ}$ at the beginning of Phase II. It then increases, reaching the maximum of $235^{\circ}$ at the beginning of Phase III (Fig. 10b). The apparent velocity has values higher than $2000 \mathrm{~m} / \mathrm{s}$ at the beginning of Phase I with a maximum close to $6000 \mathrm{~m} / \mathrm{s}$. The values are decreasing during approximately $100 \mathrm{~s}$ reaching a plateau of $2000 \mathrm{~m} / \mathrm{s}$. In Phase II, the apparent velocity slightly increases and then begins to decline sharply in the middle of the phase, reaching a minimum at the beginning of Phase III with values lower than $1000 \mathrm{~m} / \mathrm{s}$. This significant decrease occurs in about $100 \mathrm{~s}$ (Fig. 10c). Decrease of the apparent velocity during Phases I and II lasts for $350 \mathrm{~s}$. The apparent velocity remains stable with low values during most of the Phase III, then, it gradually rises at the end of Phase III, without reaching high values observed at the beginning of the eruptive phase.

Following the procedure described previously, the altitude of the seismic source was estimated for each point of apparent velocity curve using Eq. (4). We thus obtain a PDF of the apparent velocity for each point source location, the maximum of which indicates the altitude of the source. The associated error depends on how broad the function is. We considered an error equivalent to the width of the PDF at $90 \%$ of the maximum value. The obtained model of low-frequency source depth is shown in Fig. 10d. Color bar indicates the ratio between the amplitude of the signal filtered between 0.3 and $1 \mathrm{~Hz}$ and the average amplitude calculated for the same signal before the eruption, between 100 and $1000 \mathrm{~s}$. Amplitude ratio values are higher than 2 at the beginning of Phase I and exceed 10 during Phases II and III, the maximum being close to 100. The first part of the eruption (Phase I and half of Phase II) has sources located below or around $2000 \mathrm{~m} \mathrm{ASL}$, much beneath the dome (Fig. 10d). According to the evolution of the apparent velocity curve, Phase I shows a sharp ascent of the source of about $600 \mathrm{~m}$ during approximately $100 \mathrm{~s}$, then a plateau around $1900 \mathrm{~m}$ ASL. Phase II is characterized by firstly a slight descend of the source, followed by its sharp ascent between $1500 \mathrm{~s}$ and $1600 \mathrm{~s}$. This ascent is of the order of $1000 \mathrm{~m}$ and occurs in a little bit more than $100 \mathrm{~s}$. The average velocity of the source migration during Phases I and II combined is estimated to $\sim 5 \mathrm{~m} / \mathrm{s}$. The source is positioned at the surface $(\sim 2700 \mathrm{~m}$ above sea level) at the beginning of Phase III and remains stable at this level until almost the end of the event.

We finally wanted to assess whether a relation between the source depth and the back-azimuth can be observed. Fig. 11 shows the altitude of the source as a function of the back-azimuth and time from the beginning of eruption. We performed a cross section of the topography in the direction $N 335^{\circ}$. This NNW-SSE direction corresponds to the orientation of the dome fracture mentioned by Walter et al. (2015), as well as the alignment of regional tectonic structures and the direction of pyroclastic flows during the 2010 eruption. We observe that during Phase I of 
a)

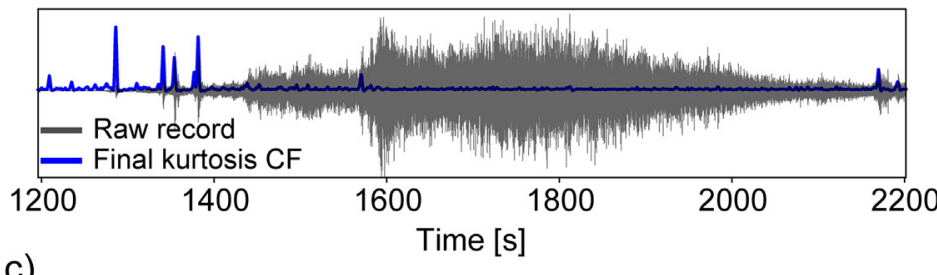

c)

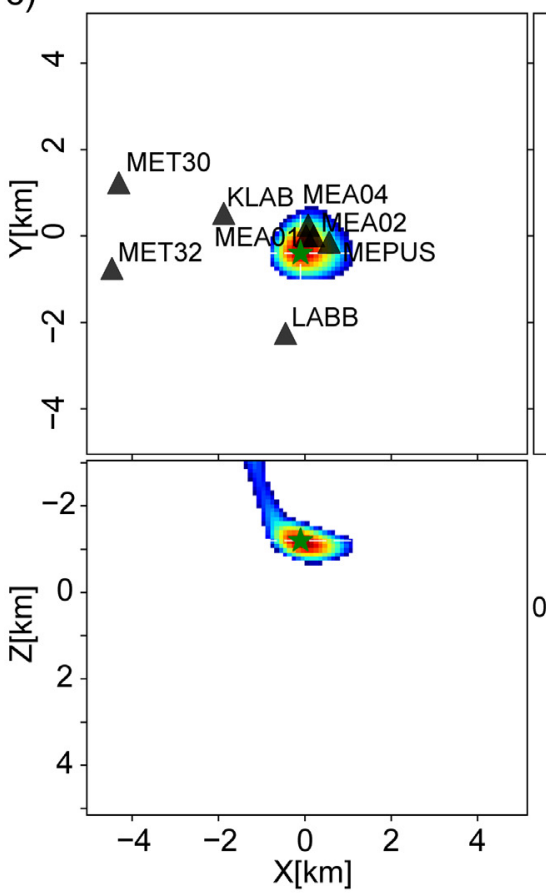

b)

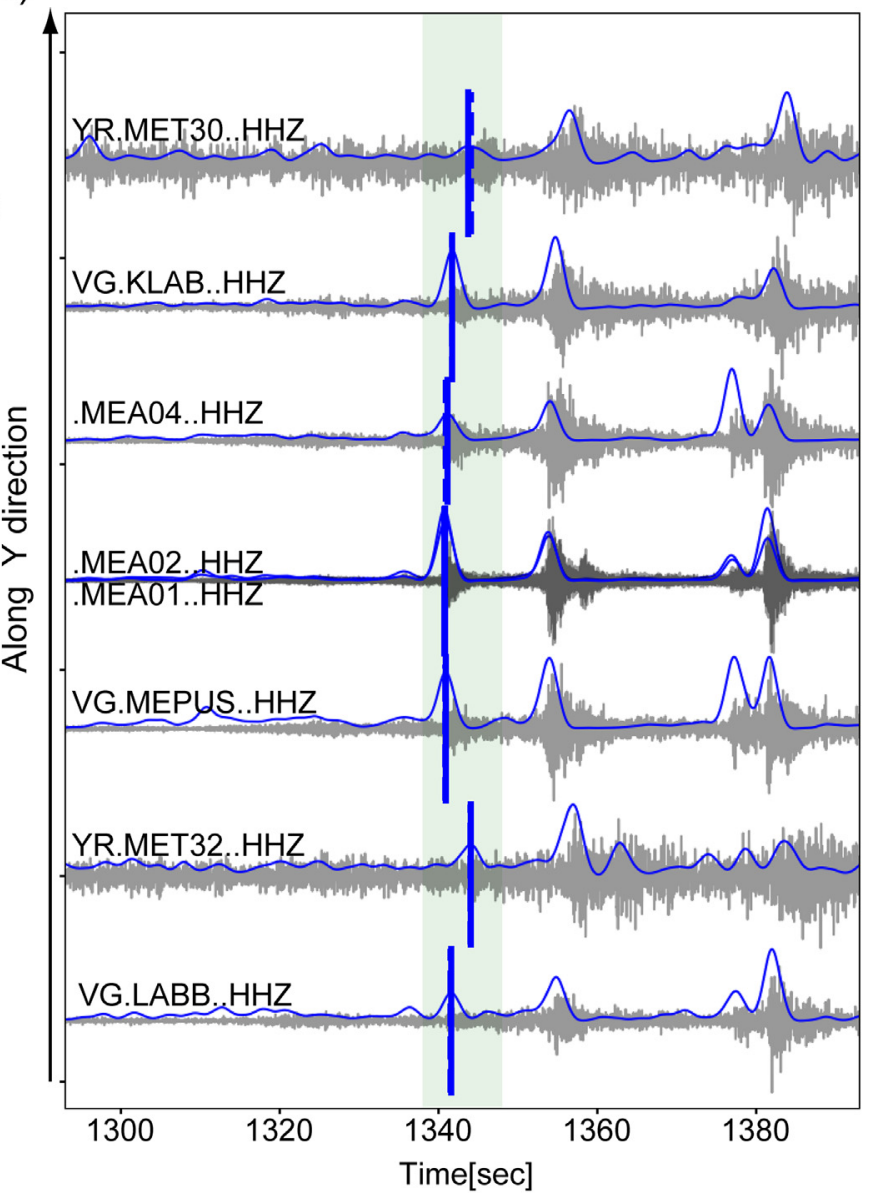

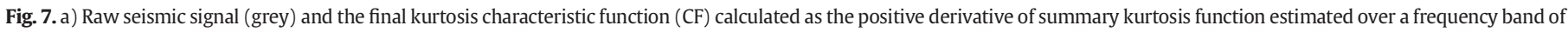

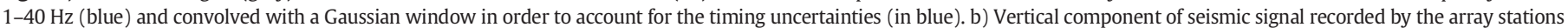

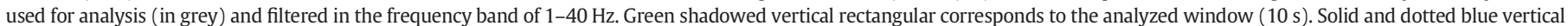

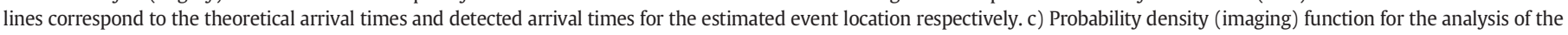

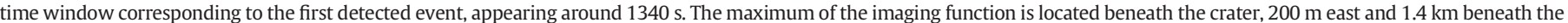
dome. Graphics are extracted from the output of the BacktrackBB code.

eruption the source is located further south, between $200^{\circ}$ and $215^{\circ}$. It then migrates to the north and up during Phase II and remains at the azimuth pointing towards the center of the dome during Phase III. We are not able to assess whether the back-azimuth evolution over time corresponds to a migration of seismicity in this direction because the exact source location can't be determined using our single seismic antenna. However, seismicity clearly migrates from south to north during its

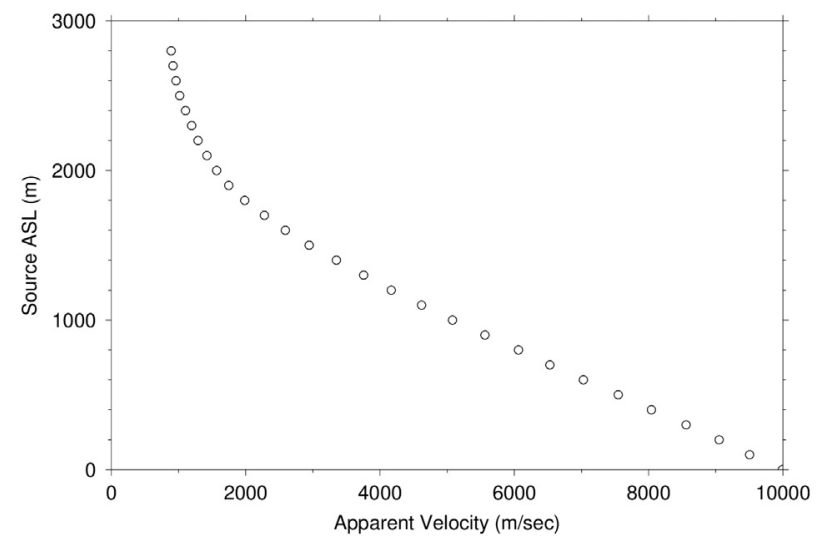

Fig. 8. Model of apparent velocity obtained for sources (open circles) positioned every $100 \mathrm{~m}$ above sea level. ascent phase towards the dome and the orientation of the fracture at the surface of the dome and the volcano topography suggest that this assumption is not meaningless. In Fig. 11 we also show the horizontal and vertical source location errors with grey bars. Those denote errors projected on the respective back-azimuth for the corresponding depth. We also represented on the same figure the location of the high frequency transients events discussed in Section 6.2. The results regarding the migration of the source of seismicity are discussed in details in Section 7.

\section{Discussion}

\subsection{Questions}

Merapi has experienced a series of phreatic or phreato-magmatic activity between 2012 and 2014. This type of activity is not common for this volcano. It is worth noting, however, that a similar type of activity occurred in the period of 1878-1879 (Voight et al., 2000), following the explosive eruption of 1872 , which was very similar to that of 2010. This similarity stresses the interest to investigate the 2012-2014 eruptive phase. This study seeks to answer several questions: 1) Is it possible to reconstruct the progression of the eruptive sequence? 2) What information can we extract about the eruptive dynamics and the geometry of the conduit? 3) Is this activity of phreatic or phreato- 
a)
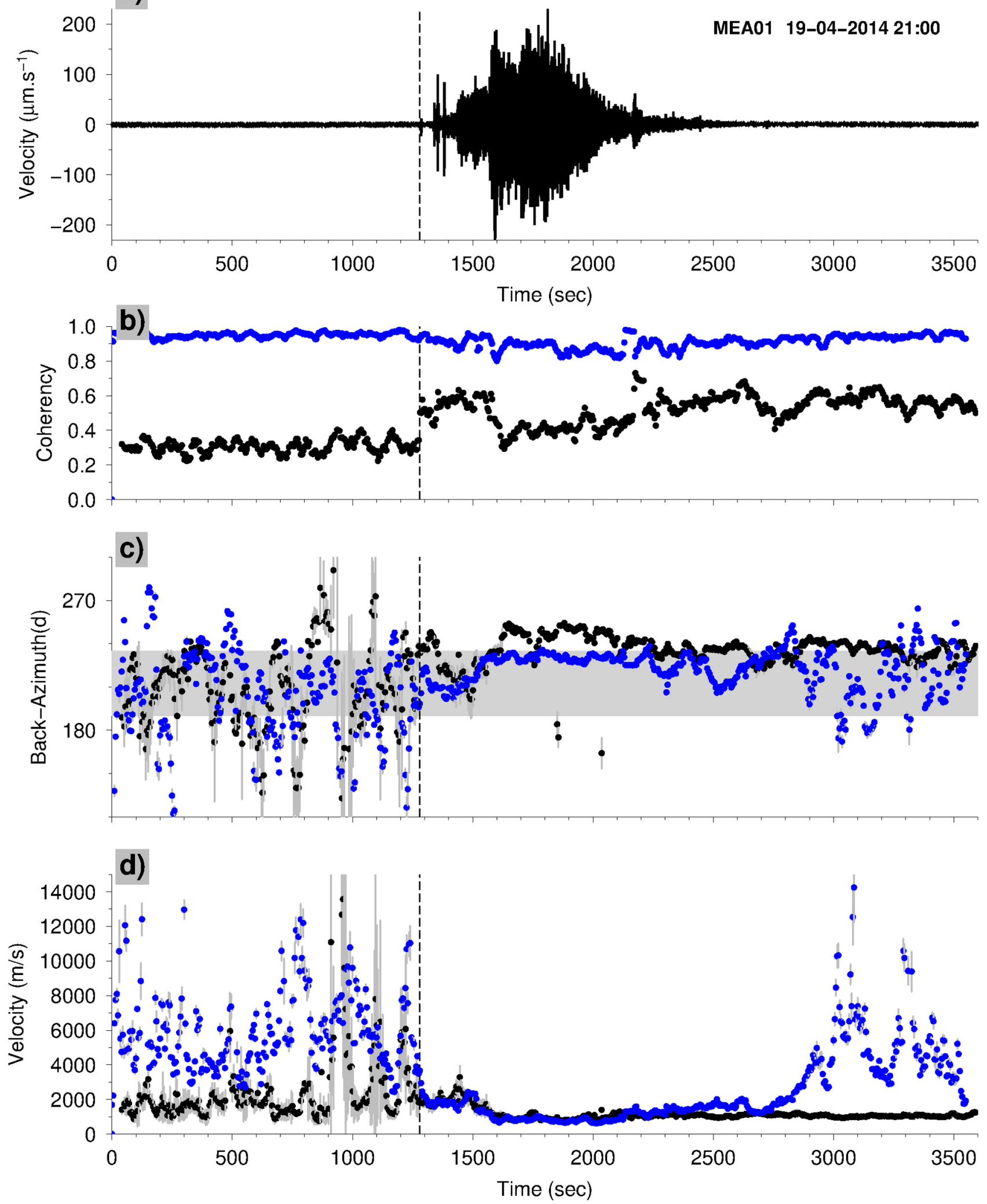

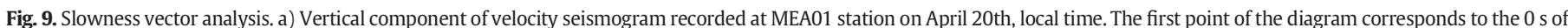

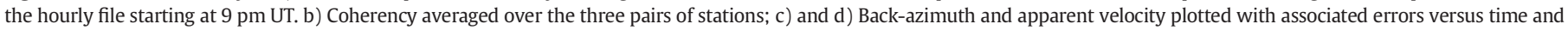

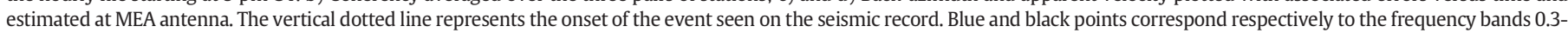
$1 \mathrm{~Hz}$ and $1-3 \mathrm{~Hz}$. 
a)
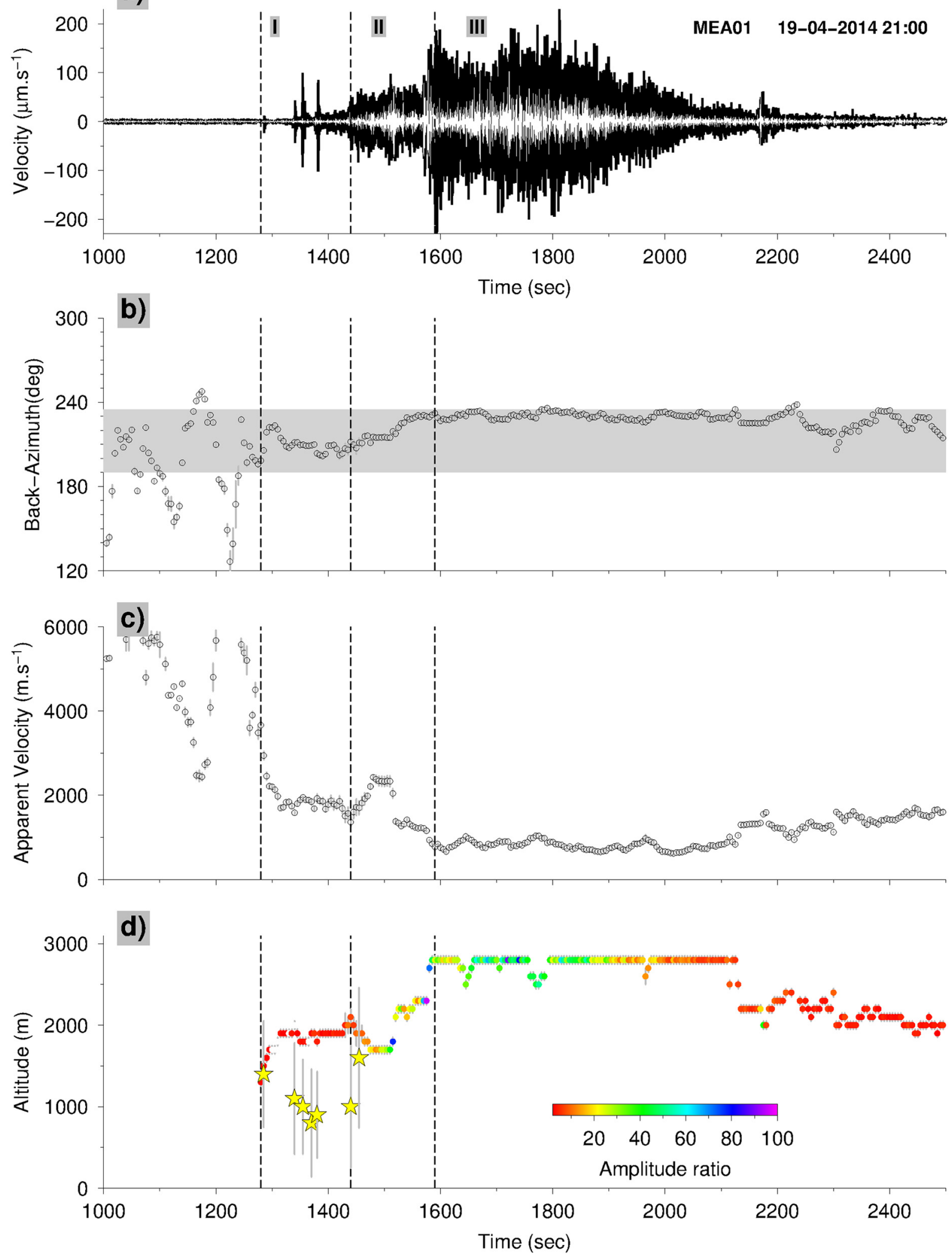

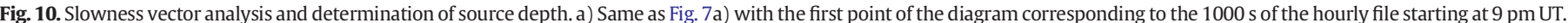

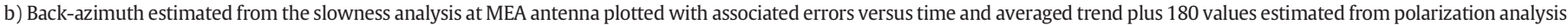

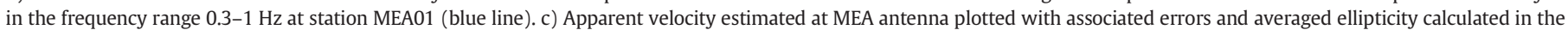

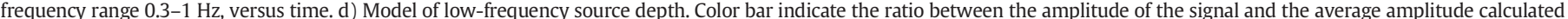

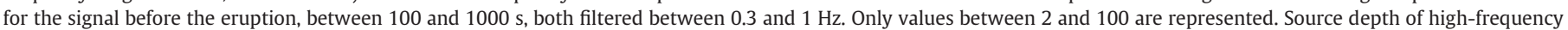

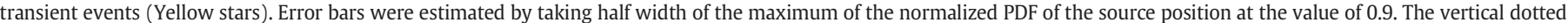
lines represent the onset of the event and the beginning of eruptive phases we identified. 
magmatic character? If magma is involved, is there juvenile magma or remobilized magma from 2010 eruption?

\subsection{Limitations}

The short aperture array technique that we used to reveal the migration of the source and information about the chronology of the eruptive process relies on the assumption of plane waves. Given the distance between the source and the receivers, this assumption is not exactly fulfilled, which may create a bias in the results. Another feature of this study is the nature of wave fields arising from the fact that sourcesensor distance is less than the wavelength. Following Madariaga (2015), far-field body waves radiated by a point source is defined by the condition $\omega \mathrm{R} / \alpha \gg 1$, where $\alpha$ is the P-wave velocity and R the distance source-station. It is equivalent to $R / \lambda \ll 1$. In the frequency band of $0.3-1 \mathrm{~Hz}, \lambda \sim 1-6 \mathrm{~km}$, we are therefore in the near-field. In the frequency band $1-3 \mathrm{~Hz}, \lambda \sim 0.2-1 \mathrm{~km}$, we are in the "intermediate-field".

We presented the results obtained by analyzing the signal filtered in both frequency bands. Similar results are obtained in the $1-3 \mathrm{~Hz}$ frequency band, except an offset of the back-azimuth values during Phase III, which corresponds to the ash emission. It is probable that during a long duration process, several types of waves interfere. The mixing of different waves would be more pronounced at higher frequencies, hence leading to a stronger dispersion of the slowness vector values. Moreover, high frequencies are expected to be more affected by the diffraction of local heterogeneity. This could also explain the lack of polarization in this frequency band. For these different reasons, we choose to focus our analysis in the frequency band $0.3-1 \mathrm{~Hz}$, which correspond to the near-field domain. There is a priori no contradiction in applying our antenna analysis method in the near-field. The main difficulty comes from the lack of resolution capabilities of the antenna due to its small aperture compared to the wavelength. For a single plane wave (or one energetically dominant source contribution) noise-free, our analysis should provide correct values of the slowness vector. Additional noise may distort the array response function. In a noisy case, the broadness of the peak can generate slowness vector values different than the correct ones. The narrower the main lobe shape in the array response function, the lower will be the noise, more correct will be the values of slowness vector. We suggest that this may explain the more dispersed values of slowness obtained for the frequency band $1-3 \mathrm{~Hz}$ and especially the non-realistic shift towards higher values of back-azimuth. Overall the general similarity of the results obtained in both frequency bands suggests that the analysis in the $0.3-1 \mathrm{~Hz}$ frequency band is reliable.

Lokmer and Bean (2010) studied the contribution of the nearfield term to the source localization for volcanic events by using synthetic signals. They showed that in such cases the deviation of the first motion polarization from the radial direction is significant and the source location may be affected when using standard methods as semblance or cross-correlation. However, this effect seems less pronounced when there is a considerable volumetric component present in the source (as in the case of a tensile crack and a pipe-like source), which implies a significant mass movement. This is a plausible hypothesis for the signal generated by the eruption of Merapi, given the dimensions of the eruptive fissure indicated by Walter et al. (2015). Another limitation of working in the frequency band $0.3-1 \mathrm{~Hz}$ is the possible contamination of the oceanic noise. We saw that for amplitude of the seismic noise recorded before the eruption is much lower than the seismic signal produced by the eruptive process. Furthermore, the wavefield is not polarized and slowness vector values are strongly dispersed before and after the eruptive signal strongly suggesting that the effect of the oceanic noise is negligible. All these elements justify the analysis of the wave fields in this frequency band. The main weakness of this study is probably the low number of sensors.

\subsection{Comparison with other phreatic eruptions}

At other volcanoes, some phreatic eruptions were found to be preceded by VLP events (e.g., Ruapehu (Jolly et al., 2010); Ontake (Maeda et al., 2015); White Island and Kawah Ijen (Caudron et al. (2018); Jolly et al. (2018)); other volcanoes (Stix and Maarten de Moor, 2018)). We do not observe any VLP precursory signal in the case of Merapi. The phreatic eruptions signals observed at other volcanoes however show the same complexity with processes involving several phases lasting from several to tens of minutes (e.g., Shinmoedake eruption Kato and Yamasato (2013); Tongariro eruption Jolly et al. (2014); Ontake eruption Ogiso et al. (2015); Kawah Ijen and White Island (Caudron et al. (2018); Jolly et al. (2018)). For example at White Island in April 2016, Walsh et al. (2019) characterized as an eruptive sequence up to six distinct pulses occurring over the first $30 \mathrm{~min}$, and a late tremor sequence lasting up to $2 \mathrm{~h}$ after the pulsing phase. The tremor lasted more than $4 \mathrm{~h}$ at Kawah Ijen in 2013 and $\sim 8 \mathrm{~h}$ at White Island in 2013 (Caudron et al., 2018). In most cases, the signals comprise a large range of frequencies. The eruption of April 20th shows at least three distinct phases with high frequency events at the beginning and 2 phases of tremor with different amplitude values. Phase I, which lasts about $180 \mathrm{~s}$, is characterized by several high-frequency micro-earthquakes with emergent onset. They are located in the crater area from $700 \mathrm{~m}$ to $1300 \mathrm{~m}$ ASL. Low-frequency [0.3-1 Hz] source migrates first from $1300 \mathrm{~m}$ to $1900 \mathrm{~m}$ ASL and then stabilize at that depth. Depth of the first micro-earthquake corresponds with depth of low-frequency tremor. Depth of the 4 following events of Phase I are deeper. Jolly et al. (2014) described a very similar phase composed of microearthquakes during the initiation of the phreatic eruption of Te Maari crater at Tongariro volcano in 2012 whereas Caudron et al. (2018) located high-frequency tremor associated with the 2013 eruption at Kawah Ijen. Jolly et al. (2014) interpreted them as increased flux of fluids which destabilised overlying hydrothermal system. Caudron et al. (2018) ascribed this seismicity to the progressive rupture of a seal in the most shallow part of the hydrothermal system as response to mass pulses transferred from VLP depths. They interpret the origin of this micro-seismicity as resulting from the influx of fluids from the shallow magma system into the hydrothermal system, leading to its destabilization. In the model proposed by Ogiso et al. (2015) for the phreatic eruption of Ontake, the eruptive process starts with a sudden decompression at a shallow depth which induces a phase transition of the volcanic fluids. We infer from these studies that microearthquakes observed in Phase I may be associated with an interaction between magmatic fluids and the hydrothermal system. The fact that micro-earthquakes depths remains between $800 \mathrm{~m}$ and $1600 \mathrm{~m}$ ASL during all the Phase I could be explained by the position of the contact zone between the magmatic fluid and the hydrothermal system at this altitude. Taking into account uncertainties of micro-earthquakes depth determination, this zone is approximately $1 \mathrm{~km}$ thick. Migration of low-frequency seismicity could correspond to the movement of fluids towards the altitude of $1800 \mathrm{~m}$, approximately $1000 \mathrm{~m}$ beneath the dome surface.

Phase II lasts for $\sim 150 \mathrm{~s}$. At low frequencies, it is characterized by a slight evolution of the back-azimuth from the south to the dome fracture and is accompanied by significant changes in source depth. It goes down at first from $2000 \mathrm{~m}$ to $1600 \mathrm{~m}$ ASL ( $700 \mathrm{~m}-1100 \mathrm{~m}$ below the dome) in a few tens of seconds, then it goes up to the altitude of $2700 \mathrm{~m}$ in $\sim 100 \mathrm{~s}$, making a descent and an ascent velocity of about $10 \mathrm{~m} / \mathrm{s}$.

The depth of high-frequency activity at the beginning of Phase II corresponds quite well with low-frequency tremor source. Ogiso et al. (2015) observed a descent of the tremor source before the 2014 phreatic eruption of Ontake, in the frequency range of 5-10 Hz. They located the tremor source by using the amplitude source location (ASL) method. According to their interpretation, decompression caused by the transition of the volcanic fluid to a gaseous phase would propagate 


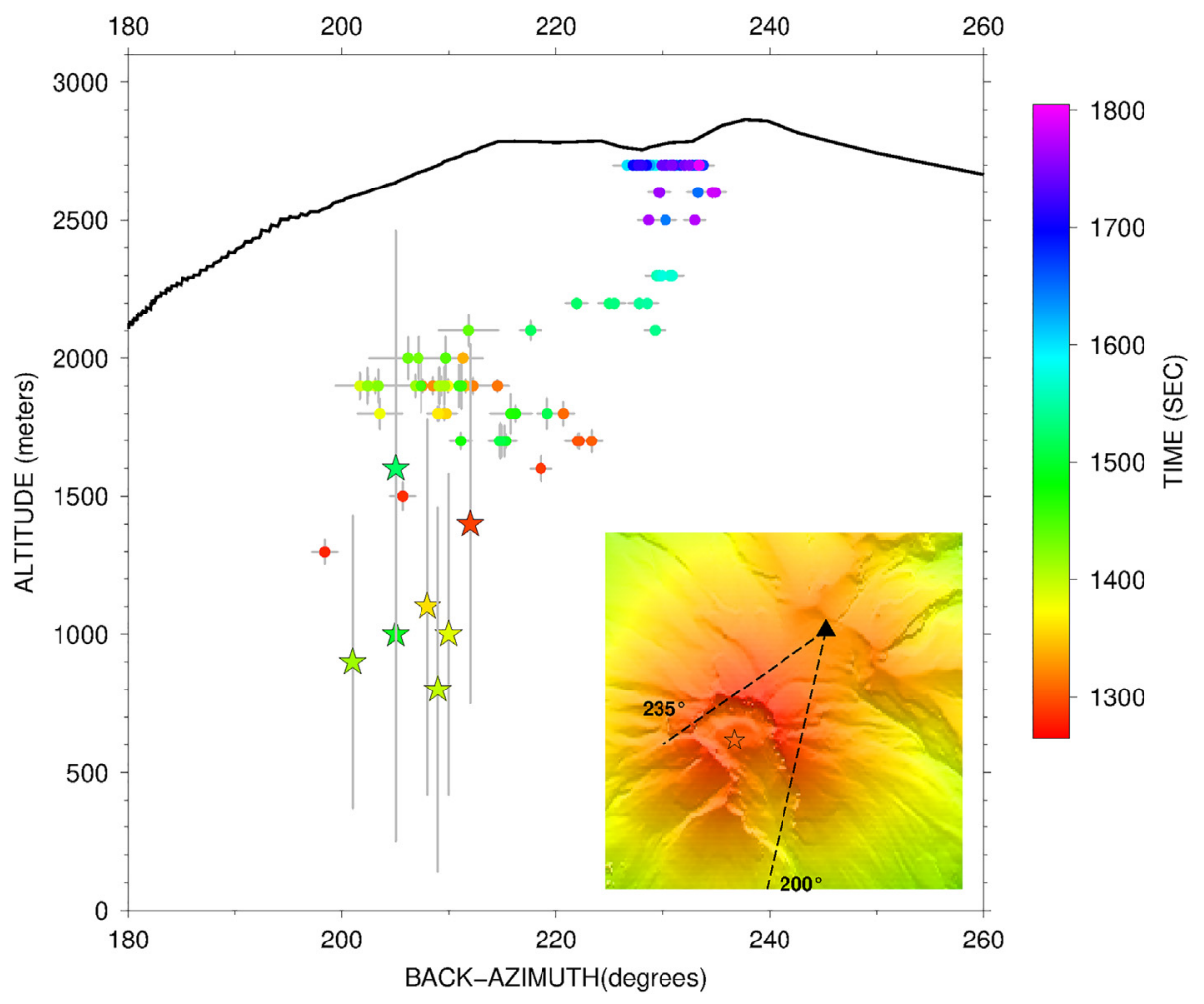

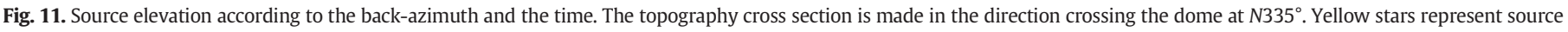

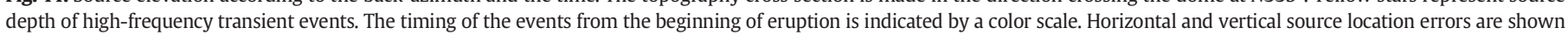
by grey bars.

simultaneously downwards in the hydrothermal systems and upward, opening cracks beneath the crater. Ascending sources have been identified by other analyses, migration of seismicity (Kato et al., 2015) and ground inflation detected by tiltmeter (Miyaoka and Takagi, 2016). At Merapi, we observe both directions of migration, but shifted in time. The location method we are using allows determining only one source position at a time, so we can not observe the phenomena moving simultaneously downwards and upward. To explain the observation of the descending and ascending migration at different times, we suggest that the seismic wavefield could be dominated by waves characterizing the descending process at the beginning of Phase II, then by waves dominated by the ascending process. We propose that high-frequency events mark a new episode of decompression caused by the transition of the volcanic fluid to a gaseous phase, initiating the second part of source migration. Ascent time of seismic sources has been studied by Jolly et al. (2018) in the case of a VLP event related to gas ascent during an eruption sequence at White Island volcano. Modelling of transfer rates of $\mathrm{CO} 2$ pulses shows a high dependence on permeability characteristics of the conduit, they found that $\mathrm{CO} 2$ transfer in a $8 \mathrm{~m}$ diameter and $800 \mathrm{~m}$ depth conduit falls within the range $0.03-1.9 \mathrm{~m} / \mathrm{s}$, for permeability values to $10^{-11}$ and $10^{-9} \mathrm{~m}^{2}$, respectively. Numerical simulations of VLP deformations produced by gas slug ascent made by O'Brien and Bean (2008) gave quite similar velocities $(0.3-0.8 \mathrm{~m} / \mathrm{s})$. Heap et al. (2019) assumed permeability values for the fractured lava dome at Merapi of maximum $10^{-11} \mathrm{~m}^{2}$, which would give, taking the same characteristics of the conduit used by Jolly et al. (2018) a gas ascent velocity 2 order of magnitude lower than the velocity estimated in our study. As suggested by Jolly et al. (2018), the bulk vent permeabilities are likely to be higher than this maximum measured value.

Beginning of Phase III is marked by the stabilization of back-azimuth at a value corresponding to the position of the eruptive fracture, with the source depth being at the dome level or just below. This phase corresponds to the highest amplitudes of the seismic signal and to a broadband spectral content composed of both low and high frequencies. It is likely that this phase corresponds to the emission of gases, steam and ash. We have no visual or geophysical observation allowing to identify unambiguously the onset of eruption with the starting of ash emission. The position of the seismic source close to the surface is a good argument to support this. It is also interesting to refer to what has been observed on other volcanoes with similar types of eruptions. In the cases of Ontake and Ruapehu-Tongariro (Te Maari vent) volcanoes, the eruptive onset was identified by video observation (Ogiso et al., 2015) and with acoustic sensors (Jolly et al., 2014). In both cases, the emission of material occurs several minutes after the first micro-earthquakes or tremors associated with the decompression process in the hydrothermal system, about $5 \mathrm{~min}$ at Te Maari and $10 \mathrm{~min}$ at Ontake. Another similar case is related to a video footage made during the 27 May 2010 eruption of Shinmoedake volcano, that clearly indicated that the tremor event started approximately $5 \mathrm{~min}$ before the eruption (Kato and Yamasato, 2013). Phase III, which is marked by a sudden increase in the amplitude, begins $5.5 \mathrm{~min}$ after the first micro-earthquake in Phase I. This, similarly to what is observed on other volcanoes, is an additional argument suggesting that the emission of ash probably began with Phase III. This period of a few minutes (i.e., 5-10 min) seems characteristic for this type of process. It could be related to the time required for the decompression of the fluid, the failure of the sealed surface of the vertical conduit or re-opening of a pre-existing path and the gas and ash ascent. Considering the location of the source of tremor close to the surface is a proxy of ash emission, this phase would have lasted in total $650 \mathrm{~s}$. The first $300 \mathrm{~s}$ have a steady amplitude, probably marking a constant flow, then a gradual decrease in energy occurs in the last $350 \mathrm{~s}$. At the end of the eruption, the source becomes deeper and seems to go back to the depth of the initiation process.

Another important result is the change in azimuth during Phase II. We observe a gradual upward migration of the source towards the north and therefore towards the dome. Although we are unable to locate the exact position of the source with a single antenna, one can nevertheless make the assumption that this migration from south to north could follow the 
dome fracture characterized by predominant NW-SE direction. This is also consistent with the alignment of regional tectonic structures (Walter et al., 2015). According to this hypothesis, the orientation of the seismic source migration shows a slight inclination of the conduit to the south or southeast. This inclination could explain the directivity of the eruption that threw blocks on the west side of the fracture (Fig. 1). Directivity of eruption deposits produced by phreatic eruptions has been observed at other volcanoes, Ontake (Tsunematsu et al., 2016), Te Maari (Lube et al., 2014; Fitzgerald et al., 2014), and Ruapehu (Kilgour et al., 2010).

After 4 years of quiescence on Merapi, a new series of phreatic eruptions occurred in May-June 2018 and was followed by a magmatic eruption that started in August 2018. The main and fundamental difference between the two periods is that 2018 phreatic eruptions appears to be precursors of the August 2018 magmatic eruption. One of the questions here was whether the hot fluids that produced phreatic eruptions in the period 2012-2014 have been produced by juvenile magma or remobilized magma from 2010 eruption. It is beyond the scope of this study to compare phreatic eruption in 2014 and 2018; a precise comparison between phreatic eruptions of 2014 and 2018 will be essential to know if the former ones have resulted from remobilized magma from 2010 or from new magmatic intrusions that, unlike 2018, could not reach the surface.

\section{Conclusion}

The analysis of the eruption from April 20, 2014, shows that the emission of ash is preceded by deep processes occurring from $900 \mathrm{~m}$ to $2700 \mathrm{~m}$ above sea level. They generate deeper high-frequency micro-seismicity and low-frequency tremor migrating towards the surface occurring in two distinct phases that we interpret as: 1) The first influx of fluids from the shallow magma system into the hydrothermal system that generates a sudden decompression caused by the transition of the volcanic fluid to a gaseous phase, production of high-frequency micro-seismicity and the migration of low-frequency tremor source; 2) A second decompression process marked by high-frequency microseismicity followed by the migration of the low-frequency tremor source denoting a descent phase and finally followed by a sharp ascent. The source migration is interpreted as the ascent of gas and volcanic ash up to the fracture formed in the dome during the eruption of November 2013. These initial phases lasting for $5.5 \mathrm{~min}$ in total could be considered as the precursor of the superficial and explosive process of the eruption. The average migration speed from the starting eruptive process to ash emission is estimated to be $5 \mathrm{~m} / \mathrm{s}$. The evolution of the back-azimuth during the migration process indicates a slight inclination of the conduit, presumably in a NW-SE direction, which corresponds to the orientation of the dome fracture and the alignment of regional tectonic structures. This orientation could explain the directivity of the eruption that threw rocks on the west side of the fracture. We interpret the whole process as the consequence of the hot fluid ascent in the hydrothermal system resulting from residual magma or a new intrusion at shallow depth. Contrary to phreatic eruptions observed at other volcanoes, Merapi's eruptions are not preceded by VLP events. This phreatic activity lasted 2 years, from 2012 to 2014. This 2 year-eruptive phase may result from the remobilized magma of 2010 or new magmatic intrusions that, unlike 2018, could not reach the surface.

\section{CRediT authorship contribution statement}

Jean-Philippe Métaxian: Conceptualization, Formal analysis, Funding acquisition, Methodology, Software, Writing - original draft. Agus Budi Santoso: Methodology, Validation. Corentin Caudron: Methodology, Writing - original draft, Validation. Noer Cholik: Data curation. Claire Labonne: Software, Writing - original draft. Natalia Poiata: Software, Writing - original draft. François Beauducel: Funding acquisition, Data curation. Vadim Monteiller: Software. Ahmad Ali Fahmi: Data curation. Muchammad Husni Rizal: Data curation. I.G. Made Agung Nandaka: Project administration.

\section{Declaration of competing interest}

There is no conflict of interest associated to this work.

\section{Acknowledgments}

We thank Ghofar Ashab for the maintenance of the seismic equipments used in this study. Figs. 2, 5 and 8 to 11 were created using the Generic Mapping Tools software (GMT) (Wessel et al., 2019). We gratefully acknowledge the French Agence Nationale de la Recherche for funding the DOMERAPI ANR project (ANR-12-BS06-0012) and BMKG for providing data used in this study. The DOMERAPI data were acquired using instruments belonging to the French national pool of portable seismic stations RESIF-SISMOB (CNRS-INSU). We Thank Marc Wathelet and Matthias Ohrnberger for expert advices about to seismic antenna resolution. Geopsy tools (http://www.geopsy.org) and associated documentation were very useful. We would like to thank editor Diana Roman and the anonymous reviewers for their constructive and stimulating suggestions.

\section{Data availability}

The DOMERAPI data used in this study are available at http://www. fdsn.org/networks/detail/YR2013/ with citation information https:// doi.org/10.15778/RESIF.YR2013.

\section{References}

Aki, K., 1957. Space and time spectra of stationary stochastic waves, with special reference to microtremors. Bull, Earthq. Res. Inst 35, 415-456.

Almendros, J., Ibáñez, J.M., Alguacil, G., Del Pezzo, E., 1999. Array analysis using circular-wavefront geometry: an application to locate the nearby seismo-volcanic source. Geophys. J. Int. 136 (1), 159-170. http://gji.oxfordjournals.org/content/136/1/159.abstract.

Almendros, J., Chouet, B., Dawson, P., 2001a. Spatial extent of a hydrothermal system at Kilauea Volcano, Hawaii, determined from array analyses of shallow long-period seismicity: 1. Method. Journal of Geophysical Research: Solid Earth 106 (B7), 13565-13580 URL. https://doi.org/10.1029/2001JB000310.

Almendros, J., Chouet, B., Dawson, P., 2001b. Spatial extent of a hydrothermal system at Kilauea Volcano, Hawaii, determined from array analyses of shallow long-period seismicity: 2. Results. Journal of Geophysical Research: Solid Earth 106 (B7) 13581-13597 URL. https://doi.org/10.1029/2001JB000309.

Barberi, F., Bertagnini, A., Landi, P., Principe, C., 1992. A review on phreatic eruptions and their precursors. J. Volcanol. Geotherm. Res. 52 (4), 231-246. http://www. sciencedirect.com/science/article/pii/037702739290046G.

Budi-Santoso, A., Lesage, P., Dwiyono, S., Sumarti, S., Subandriyo, Surono, Jousset, P. Metaxian, J.-P., 2013. Analysis of the seismic activity associated with the 2010 eruption of Merapi Volcano, Java. J. Volcanol. Geotherm. Res. 261, 153-170 merapi eruption. http://www.sciencedirect.com/science/article/pii/S0377027313001005.

Caudron, C., Girona, T., Taisne, B., Suparjan, Gunawan, H., Kristianto, K., 2019. Change in seismic attenuation as a long-term precursor of gas-driven eruptions. Geology 47 (7), 632-636. https://doi.org/10.1130/G46107.1.

Caudron, C., Taisne, B., Neuberg, J., Jolly, A.D., Christenson, B., Lecocq, T., Suparjan Syahbana, D., Suantika, G., 2018. Anatomy of phreatic eruptions. Earth Planets Space 70 (1), 168. https://doi.org/10.1186/s40623-018-0938-x.

Fitzgerald, R.H., Tsunematsu, K., Kennedy, B.M., Breard, E.C.P., Lube, G., Wilson, T.M., Jolly, A.D., Pawson, J., Rosenberg, M.D., Cronin, S.J., 2014. The application of a calibrated 3D ballistic trajectory model to ballistic hazard assessments at Upper Te Maari, Tongariro. J. Volcanol. Geotherm. Res. 286, 248-262.

Frechet, J., 1985. Sismogenese et doublets sismiques. these d etat. Univ. Sci. Technol. Medecine, Grenoble, p. 207.

Gertisser, Ralf Charbonnier, Sylvain Keller, Jörg Quidelleur, Xavier. (2012). The geological evolution of Merapi volcano, Central Java, Indonesia. Bull. Volcanol.. 74. URL https:// doi.org/10.1007/s00445-012-0591-3.

Got, J.-L., Fréchet, J., Klein, F.W., 1994. Deep fault plane geometry inferred from multiplet relative relocation beneath the south flank of Kilauea. Journal of Geophysical Research: Solid Earth 99 (B8), 15375-15386 URL. https://doi.org/10.1029/94JB00577.

Heap, M.J., Troll, V.R., Kushnir, A.R.L., et al., 2019. Hydrothermal alteration of andesitic lava domes can lead to explosive volcanic behaviour. Nat. Commun. 10 (5063). https:// doi.org/10.1038/s41467-019-13102-8.

Inza, L.A., Mars, J.I., Métaxian, J.P., O'Brien, G.S., Macedo, O., 2011. Seismo-volcano source localization with triaxial broad-band seismic array. Geophys. J. Int. 187 (1) 371-384. http://gji.oxfordjournals.org/content/187/1/371.abstract.

Inza, L., Métaxian, J., Mars, J., Bean, C., O'Brien, G., Macedo, O., Zandomeneghi, D., 2014 Analysis of dynamics of vulcanian activity of Ubinas volcano, using multicomponen seismic antennas. J. Volcanol. Geotherm. Res. 270, 35-52. http://www.sciencedirect. com/science/article/pii/S0377027313003442.

Jenkins, G., Watts, D., 1998. Spectral Analysis and Its Applications. Holden-Day Series in Time Series AnalysisHolden-Day https://books.google.co.id/books?id=ZOl9nQEACAAJ. 
Jolly, A.D., Sherburn, S., Jousset, P., Kilgour, G., 2010. Eruption source processes derived from seismic and acoustic observations of the 25 September 2007 Ruapehu eruption-North Island, New Zealand. J. Volcanol. Geotherm. Res. (ISSN: 0377-0273) 191 (1-2), 33-45. http://www.sciencedirect.com/science/article/pii/S0377027310000235.

Jolly, A., Jousset, P., Lyons, J., Carniel, R., Fournier, N., Fry, B., Miller, C., 2014. Seismoacoustic evidence for an avalanche driven phreatic eruption through a beheaded hydrothermal system: an example from the 2012 Tongariro eruption. J. Volcanol. Geotherm. Res. 286, 331-347. http://www.sciencedirect.com/science/article/pii/ S0377027314001176.

Jolly, Arthur, Lokmer, Ivan, Christenson, Bruce, Thun, Johannes, 2018. Relating gas ascent to eruption triggering for the April 27, 2016, White Island (Whakaari), New Zealand eruption sequence. Earth, Planets and Space 70. https://doi.org/10.1186/s40623-0180948-8.

Jousset, P., Pallister, J., Surono, 2013. The 2010 eruption of Merapi volcano. J. Volcanol. Geotherm. Res. 261, 1-6 merapi eruption. http://www.sciencedirect.com/science/article/pii/S0377027313001492.

Kato, K., Yamasato, H., 2013. The 2011 eruptive activity of Shinmoedake volcano Kirishimayama, Kyushu, Japan-overview of activity and volcanic alert level of the Japan meteorological agency-. Earth, Planets and Space 65 (6), 489-504. https:// doi.org/10.5047/eps.2013.05.009.

Kato, A., Terakawa, T., Yamanaka, Y., Maeda, Y., Horikawa, S., Matsuhiro, K., Okuda, T. 2015. Preparatory and precursory processes leading up to the 2014 phreatic eruption of Mount Ontake, Japan. Earth, Planets and Space 67 (1), 1-11 URL. https://doi.org/ 10.1186/s40623-015-0288-X.

Kilgour, G., Manville, V., Della Pasqua, F., Graettinger, A., Hodgson, K.A., Jolly, G.E., 2010 The 25 September 2007 eruption of Mount Ruapehu, New Zealand: directed ballistics, surtseyan jets, and ice-slurry lahars. J. Volcanol. Geotherm. Res. 191, 1-14.

Kobayashi, T., Morishita, Y., Munekane, H., 2018. First detection of precursory ground inflation of a small phreatic eruption by InSAR. Earth Planet. Sci. Lett. 491, 244-254.

Köhler, A., Ohrnberger, M., Scherbaum, F., Wathelet, M., Cornou, C., 2007. Assessing the reliability of the modified three-component spatial autocorrelation technique. Geophys. J. Int. 168 (2), 779-796.

Komorowski, J.-C., Jenkins, S., Baxter, P. J., Picquout, A., Lavigne, F., Charbonnier, S., Gertisser, R., Preece, K., Cholik, N., Budi-Santoso, A., Surono, 2013. Paroxysmal dome explosion during the Merapi 2010 eruption: processes and facies relationships of associated high-energy pyroclastic density currents. J. Volcanol. Geotherm. Res. 261, 260 - 294, merapi eruption. URL http://www.sciencedirect.com/science/article/pii/ S0377027313000176

Labonne, C., Sèbe, O., Gaffet, S., Schindelé, F., Boyer, D., Decitre, J.B., Cavaillou, A., 2016. Seismic wavefield polarization-part II: Definition of a parameter system in threedimensional (3D) space, example case review using LSBB seismic station data. E3S Web of Conferences. 12. EDP Sciences, p. 06002.

Lesage, P., Heap, M.J., Kushnir, A., 2018. A generic model for the shallow velocity structure of volcanoes. J. Volcanol. Geotherm. Res. 356, 114-126 URL. https://doi.org/10.1016/j. jvolgeores.2018.03.003.

Lokmer, I., Bean, C.J., 2010. Properties of the near-field term and its effect on polarisation analysis and source locations of long-period (lp) and very-long-period (vlp) seismic events at volcanoes. J. Volcanol. Geotherm. Res. 192 (1-2), 35-47. http://www. sciencedirect.com/science/article/pii/S0377027310000521.

Lomax, A., 2005. A reanalysis of the hypocentral location and related observations for the Great 1906 California Earthquake. Bull. Seism. Soc. Am. 95, 861-877.

Lomax, A., 2008. Location and tectonics of the focal region of the California Earthquake of 18 April 1906. Bull. Seism. Soc. Am. 98, 846-860.

Lube, G., Breard, Eric C.P., Cronin, Shane J., Procter, Jonathan N., Brenna, Marco, Moebis, Anja, Pardo, Natalia, Stewart, Robert B., Jolly, Arthur, Fournier, Nicolas, 2014. Dynamics of surges generated by hydrothermal blasts during the 6 August 2012 Te Maar eruption, Mt. Tongariro, New Zealand. J. Volcanol. Geotherm. Res. 286, 348-366.

Lühr, B.-G., Maerklin, N., Rabbel, W., Wegler, U., Zschau, J., Westerhaus, M., 1998. Active seismic measurements at the Merapi volcano, Java, Indonesia. Decade-volcanoes Under Investigation, Vol. Sonderband III/1998 of DGG-Mitteilungen. Deutsche Geophysikalische Gesellschaft, pp. 53-55.

Madariaga, R., 2015. Seismic source theory. In: Schubert, Gerald (Ed.), Treatise of Geophysics, Reference Work, 2nd editionEarthquake Seismology Volume 4, pp. 51-71 2015, Editor-in-Chief.

Maeda, Y., Kato, A., Terakawa, T., et al., 2015. Source mechanism of a VLP event immediately before the 2014 eruption of Mt. Ontake, Japan. Earth Planet Sp 67 (187). https:// doi.org/10.1186/s40623-015-0358-0.

Métaxian, J.-P., Lesage, P., Valette, B., 2002. Locating sources of volcanic tremor and emergent events by seismic triangulation: application to Arenal volcano, Costa Rica. Journal of Geophysical Research: Solid Earth 107 (B10), 2243 ECV 10-1-ECV 10-18. URL https://doi.org/10.1029/2001JB000559.

Miyaoka, K., Takagi, A., 2016. Detection of crustal deformation prior to the $2014 \mathrm{Mt}$ Ontake eruption by the stacking method. Earth, Planets and Space 68 (1), 1-8. https://doi.org/10.1186/s40623-016-0439-8.

Monteiller, V., Got, J.-L., Virieux, J., Okubo, P., 2005. An efficient algorithm for doubledifference tomography and location in heterogeneous media, with an application to the Kilauea volcano. J. Geophys. Res. 110, B12306. https://doi.org/10.1029/ 2004JB003466.
O'Brien, G.S., Bean, C.J., 2008. Seismicity on volcanoes generated by gas slug ascent. Geophys. Res. Lett. 35, L16308.

Ogiso, M., Matsubayashi, H., Yamamoto, T., 2015. Descent of tremor source locations before the 2014 phreatic eruption of Ontake volcano, Japan. Earth, Planets and Space 67 (1), 1-12. https://doi.org/10.1186/s40623-015-0376-y.

Pinnegar, C.R., 2006. Polarization analysis and polarization filtering of three-component signals with the time-frequency S transform. Geophys. J. Int. 165 (2), 596-606. https://doi.org/10.1111/j.1365-246X.2006.02937.x.

Podvin, P., Lecomte, I., 1991. Finite difference computation of traveltimes in very contrasted velocity models: a massively parallel approach and its associated tools. Geophys. J. Int. 105, 271-295.

Poiata, N., Satriano, C., Vilotte, J.-P., Bernard, P., Obara, K., 1 June 2016. Multi-band array detection and location of seismic sources recorded by dense seismic networks. Geophys. J. Int. 205 (3), 1548-1573 URL. https://doi.org/10.1093/gji/ggw071.

Poupinet, G., Ellsworth, W.L., Frechet, J., 1984. Monitoring velocity variations in the crust using earthquake doublets: an application to the Calaveras Fault, California. Journal of Geophysical Research: Solid Earth 89 (B7), 5719-5731 URL. https://doi.org/10.1007/ s11589-017-0178-3.

Ramdhan, M., Widiyantoro, S., Nugraha, A., Métaxian, J.-P., Saepuloh, A., Kristyawan, S., Sembiring, A., Santoso, A.B., Laurin, A., Fahmi, A.A., 2017. Relocation of hypocenters from DOMERAPI and BMKG networks: a preliminary result from DOMERAPI project. Earthq. Sci. 30 (2), 67-79 URL. https://doi.org/10.1093/gii/gow071.

Rocca, M.L., Saccorotti, G., Pezzo, E.D., Ibanez, J., 2004. Probabilistic source location of explosion quakes at Stromboli volcano estimated with double array data. J. Volcanol. Geotherm. Res. 131 (1-2), 123-142. http://www.sciencedirect.com/science/article/ pii/S0377027303003214.

Roman, D.C., Rodgers, M., Geirsson, H., LaFemina, P.C., Tenorio, V., 2016. Assessing the likelihood and magnitude of volcanic explosions based on seismic quiescence. Earth Planet. Sci. Lett. 450, 20-28.

Rouwet, D., Sandri, L., Marzocchi, W., Gottsmann, J., Selva, J., Tonini, R., Papale, P., 2014. Recognizing and tracking volcanic hazards related to non-magmatic unrest: a review. J. Appl. Volcanol. 3 (1), 1-17. https://doi.org/10.1186/s13617-014-0017-3.

Saccorotti, G., Del Pezzo, E., 2000. A probabilistic approach to the inversion of data from a seismic array and its application to volcanic signals. Geophys. J. Int. 143 (1), 249-261. https://doi.org/10.1046/j.1365-246x.2000.00252.x.

Sano, Y., Kagoshima, T., Takahata, N., Nishio, Y., Roulleau, E., Pinti, D., Fischer, T., 2015. Tenyear helium anomaly prior to the 2014 Mt Ontake eruption. Sci. Rep. 5, 13069.

Stix, John, Maarten de Moor, J., 2018. Understanding and forecasting phreatic eruptions driven by magmatic degassing. Earth Planets Space 70, 83.

Stockwell, R.G., Mansinha, L., Lowe, R.P., 1996. Localization of the complex spectrum: the S transform. IEEE Trans. Signal Process. 44 (4), 998-1001.

Tarantola, A., Valette, B., 1982. Generalized nonlinear inverse problems solved using the least squares criterion. Rev. Geophys. 28, 219-232.

Terakawa, T., Kato, A., Yamanaka, Y., Maeda, Y., Horikawa, S., Matsuhiro, K., Okuda, T., 2016. Monitoring eruption activity using temporal stress changes at Mount Ontake volcano. Nat. Commun. 7, 10797.

Tsunematsu, K., Ishimine, Y., Kaneko, T., et al., 2016. Estimation of ballistic block landing energy during 2014 Mount Ontake eruption. Earth Planet Sp 68 (88). https://doi. org/10.1186/s40623-016-0463-8.

Voight, B., Constantine, E., Siswowidjoyo, S., Torley, R., 2000. Historical eruptions of Merapi Volcano, Central Java, Indonesia, 1768-1998. J. Volcanol. Geotherm. Res. 100 (1-4), 69-138 URL http://www.sciencedirect.com/science/article/pii/ S0377027300001347.

Walsh, B., Procter, J., Lokmer, I., et al., 2019. Geophysical examination of the 27 April 2016 Whakaari/White Island, New Zealand, eruption and its implications for vent physiognomies and eruptive dynamics. Earth Planets Space 71, 25. https://doi.org/10.1186/ s40623-019-1003-0.

Walter, T., Subandriyo, J., Kirbani, S., Bathke, H., Suryanto, W., Aisyah, N., Darmawan, H., Jousset, P., Luehr, B.-G., Dahm, T., 2015. Volcano-tectonic control of Merapi's lava dome splitting: the November 2013 fracture observed from high resolution TerraSAR-X data. Tectonophysics 639, 23-33. http://www.sciencedirect.com/science/article/pii/S004019511400585X.

Wathelet, M., 2008. An improved neighborhood algorithm: parameter conditions and dynamic scaling. Geophys. Res. Lett. 35, L09301. https://doi.org/10.1029/ 2008GL033256.

Wathelet, M., Jongmans, D., Ohrnberger, M., 2005. Direct Inversion of spatial autocorrelation curves with the neighborhood algorithm. Bull. Seismol. Soc. Am. 95, 1787-1800.

Wegler, U., Luhr, B.-G., 2001. Scattering behaviour at Merapi volcano (Java) revealed from an active seismic experiment. Geophys. J. Int. 145 (3), 579-592 URL. https://doi.org/ 10.1046/j.1365-246x.2001.01390.x.

Wessel, P., Luis, J., Uieda, L., Scharroo, R., Wobbe, F., Smith, W.H.F., Tian, D., 2019. The generic mapping tools version 6. Geochem. Geophys. Geosyst. 20. https:/doi.org/ 10.1029/2019GC008515 URL.

Widiyantoro, S., Ramdhan, M., Métaxian, J.P., Cummins, P., Martel, C., Erdmann, S., Nugraha, A., Budi-santoso, A., Laurin, A., Fahmi, A., 2018. Seismic imaging and petrology explain highly explosive eruptions of Merapi Volcano, Indonesia. Sci. Rep. 8 (1). https://doi.org/10.1038/s41598-018-31293-w December. 